\title{
Reconstructing the Malaysian 370 Flight Trajectory by Optimal Search
}

\author{
Octavian Thor Pleter, Cristian Emil Constantinescu and \\ Barna Istvan Jakab
}

(University Politehnica of Bucharest, 060042 Bucharest, Romania)

(E-mail: otp@brainbond.ro)

\begin{abstract}
In the aftermath of the disappearance of the Malaysian 370 (MH370) flight in March 2014, new positioning methods were employed to establish the search area. In the absence of all other positioning technologies (Transponder, Radio communications, Radar), these innovative methods are based on the handshake signals between an INMARSAT satellite and the satellite transceiver on board the aircraft. The log of these signals was made public in order for the scientific community to engage in solving the mystery of the MH370 trajectory. The $\log$ indicates the delay between the interrogation and response signals, as well as the relative velocity indications, based on the shift of the carrier frequency due to the Doppler-Fizeau effect. This paper puts forward an original, independent and accurate positioning method and allows the calculation of the MH370 trajectory considering the wind vector field that day, the accurate satellite orbit and an accurate model of the Earth (the WGS-84 ellipsoid). The results were compared to other results published, indicating a different final position of the aircraft from the locations of the published search area.
\end{abstract}

\section{KEYWORDS}

1. MH370. 2. Trajectory. 3. Search and Rescue (SAR).

Submitted: 13 January 2015. Accepted: 1 July 2015. First published online: 30 July 2015.

1. INTRODUCTION. On 8 March 2014, the flight Malaysian 370 from Kuala Lumpur to Beijing disappeared without any trace. The aircraft was a Boeing 777200ER (777-2H6ER, ICAO type designator B772) with the registration 9M-MRO. After 32 minutes of flight preparation, the aircraft took off and flew normally for 49 minutes. After the crucial point of IGARI at the border between Malaysian and Vietnamese airspace, the aircraft made abnormal manoeuvres for 1 hour and 17 minutes (turns, climbs, descents) then settled for a long range flight of 5 hours and 42 minutes. The total time flown abnormally was 7 hours, most probably until the fuel was exhausted. The long range en route flight of almost 6 hours was probably under automated guidance, very probably following a keyboard input flight plan changed earlier during the flight. Although all communication systems were shut down in a time window of 12 minutes (from 1709Z to 1721Z), the SATCOM satellite transponder continued to be functional and provided a number of very important clues 
Table 1. MH370 Flight Phases.

\begin{tabular}{|c|c|c|c|c|}
\hline From & To & Phase & Duration & No \\
\hline $\begin{array}{l}\text { 2014 March } 8 \\
\text { 00:00:13 (1600Z) }\end{array}$ & 00:32:13 (1632Z) & Flight preparation & $32^{\prime} 0^{\prime \prime}$ & 1 \\
\hline & & Start of flight & $32^{\prime}$ & \\
\hline 00:32:14 (1632Z) & 00:40:38 (1641Z) & Push-back, start and taxi & $8^{\prime} 26^{\prime \prime}$ & 2 \\
\hline 00:40:38 (1641Z) & 01:01:16 (1701Z) & Take-off and climb & $20^{\prime} 38^{\prime \prime}$ & 3 \\
\hline 01:01:16 (1701Z) & 01:21:04 (1721Z) & En route to IGARI & $19^{\prime} 48^{\prime \prime}$ & 4 \\
\hline & & $\begin{array}{l}\text { End of normal flight I Start of abnormal } \\
\text { manoeuvers under military surveillance }\end{array}$ & $49^{\prime}$ & \\
\hline 01:21:04 (1721Z) & 02:22:00 (1822Z) & Manoeuvers under military surveillance & $1 \mathrm{~h} 0^{\prime} 56^{\prime \prime}$ & 5 \\
\hline & 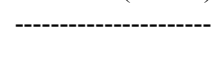 & $\begin{array}{l}\text { End of abnormal manoeuvers / Start of unknown } \\
\text { flight }\end{array}$ & 1 h $\mathbf{1}^{\prime}$ & \\
\hline 02:22:00 (1822Z) & $\begin{array}{l}\text { 02:38:00 (1838Z) } \\
?\end{array}$ & $\begin{array}{l}\text { Unknown continuation of the flight, including } \\
\text { a turn onto a new flight track }\end{array}$ & Max $16^{\prime}$ & 6 \\
\hline $\begin{array}{l}\text { 02:38:00 (1838Z) } \\
\text { ? }\end{array}$ & 08:19:29 (0019Z) & Unknown en route flight & $\underset{42^{\prime}}{\operatorname{Min} 5 \mathrm{~h}}$ & 7 \\
\hline $\begin{array}{l}\text { 08:19:29 (0019Z) } \\
?\end{array}$ & $\begin{array}{l}08: 28: 29(0028 \mathrm{Z}) \\
?\end{array}$ & $\begin{array}{l}\text { Glide descent with both engines out due to fuel } \\
\text { starvation, until crash }\end{array}$ & $\approx 9^{\prime}$ & 8 \\
\hline & & End of flight & 6 h $07^{\prime}$ & \\
\hline
\end{tabular}

about flight MH370. This paper is the result of the original work of the authors, calculating all trajectories of the aircraft consistent with a single turn after loss of ground radar contact. Also, an optimisation cycle was used to calculate the most probable trajectories, which fit best on all the data known. The results are surprising, because they indicate a position where the flight could have ended, which is different from the past and the current search areas. Besides its scientific relevance, the authors hope that their work will prove useful in the future search operations.

2. MH370 FLIGHT FACTS. Malaysian Airlines 370 took off with 239 Persons On Board (POB) (227 passengers out of the capacity of 282 and 12 members of crew). The initial flight plan was from Kuala Lumpur International (KLIA) to Beijing Capital International Airport (ZBAA). The ETA (Estimated Time of Arrival at planned destination (UTC)) was 2230Z and ETE (Estimated Time En route (estimated duration of flight in hours and minutes)) was 05:49. The fuel load was 49,100 kg, enough for over eight hours of flight. The MH370 flight phases are described in Table 1. Table 2 provides a detailed sequence of known facts about the flight, including the seven relevant ping exchanges between the INMARSAT-3 Indian Ocean Region (IOR) satellite and the SATCOM transceiver, which allow the calculation of the flight trajectory. The key moments of the flight are defined in Table 3.

The signal delay is called BTO (Burst Timing Offset) and it is caused by the time the radio waves take to travel from the satellite ground station to the satellite to the aircraft and back. Based on this, the instantaneous distance between the satellite and the aircraft (range) may be calculated for each ping exchange. The calculations presented in this paper rely mainly on these BTOs.

The locus of the points within a certain range is a sphere with the centre in the satellite position, with the range as the radius. This sphere may be intersected with the surface parallel to the ellipsoid or the geoid, at an altitude above the geoid, which 
Table 2. Sequence of Known Facts about MH370.

\begin{tabular}{|c|c|c|}
\hline Time & Event of the Flight MH370 & Reference \\
\hline $\begin{array}{l}2014 \text { March } 8 \\
\text { 00:00:13 (1600Z) }\end{array}$ & INMARSAT I-3 IOR Log-On & Avionics Power Up \\
\hline 00:07:00 (1607Z) & $\begin{array}{l}\text { First Air DATA-2 ACARS }{ }^{1} \text { message BFO } 86-90 \mathrm{~Hz} \\
\text { BTO } 14780-14900 \mu \mathrm{s}\end{array}$ & First ACARS \\
\hline 00:25:53 (1626Z) & "Delivery Malaysian Three Seven Zero good morning" & ATC Delivery contact \\
\hline 00:27:27 (1627Z) & $\begin{array}{l}\text { "Ground Malaysian Three Seven Zero good morning } \\
\text { Charlie One requesting push and start" }\end{array}$ & LUMPUR GND contact \\
\hline 00:29:00 (1629Z) & ACARS message BFO $98-100 \mathrm{~Hz}$ BTO $14920-14940 \mu \mathrm{s}$ & \\
\hline 00:32:13 (1632Z) & "Malaysian Three Seven Zero request taxi" & \\
\hline 00:36:30 (1637Z) & "Tower Malaysian Three Seven Zero morning" & LUMPUR TWR contact \\
\hline 00:40:38 (1641Z) & $\begin{array}{l}\text { TWR: "Three Seven Zero Three Two Right Cleared for } \\
\text { take-off good night" MH370: "Three Two Right Cleared } \\
\text { for take-off Malaysian Three Seven Zero thank you bye" }\end{array}$ & $\mathrm{T} / \mathrm{O}$ clearance \\
\hline 00:41:43 (1642Z) & Take-Off RWY 32R KLIA & \\
\hline 00:42:05 (1642Z) & "Departure Malaysian Three Seven Zero" & LUMPUR APP contact \\
\hline 00:42:07 (1642Z) & Cleared to climb to FL180 Direct IGARI & \\
\hline 00:42:52 (1643Z) & $\begin{array}{l}\text { Transferred from LUMPUR APP to LUMPUR } \\
\text { RADAR }\end{array}$ & \\
\hline 00:46:51 (1647Z) & "Lumpur Control Malaysian Three Seven Zero" & LUMPUR ACC contact \\
\hline 00:46:51 (1647Z) & Cleared to climb to FL250 & \\
\hline 00:50:06 (1650Z) & Cleared to climb to FL350 & \\
\hline 00:55:00 (1655Z) & ACARS message BFO $155-156 \mathrm{~Hz}$ BTO $15200-15220 \mu \mathrm{s}$ & \\
\hline 01:01:16 (1701Z) & $\begin{array}{l}\text { Pilot reports maintaining FL350 (unnecessary, } \\
\text { unsolicited) } \\
\text { HDG } 025 \text { GS } 471 \mathrm{kts}\end{array}$ & Strange human action \\
\hline 01:07:49 (1708Z) & $\begin{array}{l}\text { Last Air DATA-2 ACARS message BFO } 131 \mathrm{~Hz} \text { BTO } \\
15620 \mu \mathrm{s}\end{array}$ & Last ACARS \\
\hline 01:07:55 (1708Z) & $\begin{array}{l}\text { Pilot reports maintaining FL350 (unnecessary, unsolicit- } \\
\text { ed, repeated) }\end{array}$ & Strange human action \\
\hline 01:09:00 (1709Z) & FMS flight plan changed from the keyboard & (unconfirmed) \\
\hline 01:19:24 (1719Z) & $\begin{array}{l}\text { Transferred from LUMPUR RADAR }{ }^{2} \text { to HCM ATCC } \\
\text { on } 120 \cdot 9 \mathrm{MHz} \text { - Last transmission from cockpit: } \\
\text { "Good Night Malaysian Three Seven Zero" }\end{array}$ & Last COM \\
\hline 01:21:04 (1721Z) & $\begin{array}{l}\text { Fly over IGARI N06 } 55^{\prime} 15^{\prime \prime} \mathrm{E} 103^{\circ} 34^{\prime} 43^{\prime \prime} \text { (as tracked by } \\
\text { LUMPUR RADAR) } \mathrm{FOB}^{4} \text { for } 8 \text { hours of flight }\end{array}$ & Exit Malaysian airspace \\
\hline 01:21:13 (1721Z) & Transponder switched off or failed & Last $\mathrm{XPDR}^{5}$ \\
\hline 01:22:00 (1722Z) & Turn Left HDG & $\operatorname{PSR}^{6}$ data \\
\hline 01:30:00 (1730Z) & $\begin{array}{l}\text { HCM ACC requests other aircraft to relay communica- } \\
\text { tions to MHA } 370 \text { - no answer }\end{array}$ & No COM \\
\hline \multirow[t]{3}{*}{ 01:37:00 (1737Z) } & Expected ACARS message not transmitted & No ACARS \\
\hline & Climb to FL450 & PSR data \\
\hline & Descend to FL120 (or lower) & PSR data \\
\hline 02:03:42 (1804Z) & $\begin{array}{l}\text { No response to Air DATA-2 ACARS - ACARS failed or } \\
\text { has been switched off between } 01: 07: 49 \text { and } 02: 03: 41\end{array}$ & Proof of no ACARS \\
\hline 02:22:00 (1822Z) & $\begin{array}{l}200 \text { NM NW of Pinang - Last Military Primary Radar } \\
\text { contact }\end{array}$ & Last PSR contact \\
\hline 02:25:28 (1825Z) & $\begin{array}{l}\text { Ping Log-On request from aircraft BFO } 142 \mathrm{~Hz} \text { BTO } \\
17120 \mu \mathrm{s}\end{array}$ & \\
\hline 02:25:34 (1825Z) & Ping handshake BFO $273 \mathrm{~Hz}$ BTO $51700 \mu \mathrm{s}$ & \\
\hline 02:27:04 (1827Z) & Ping handshake BFO $175-176 \mathrm{~Hz}$ BTO $12560-12520 \mu \mathrm{s}$ & \\
\hline 02:28:06 (1828Z) & Ping handshake BFO $144 \mathrm{~Hz}$ BTO $12500 \mu \mathrm{s}$ & \\
\hline 02:28:15 (1828Z) & Ping handshake BFO $143 \mathrm{~Hz}$ BTO $12480 \mu \mathrm{s}$ & \\
\hline
\end{tabular}


Table 2. (Continued)

\begin{tabular}{|c|c|c|}
\hline Time & Event of the Flight MH370 & Reference \\
\hline 02:39:53 (1840Z) & Ground initiated Air Telephony call & \\
\hline 02:40:56 (1841Z) & No answer - Ping handshake BFO $88-90 \mathrm{~Hz}$ & Strange human action \\
\hline 02:41:00 (1841Z) & ACC Subang notifies about losing the flight & Aircraft on a new track \\
\hline 03:41:03 (1941Z) & Ping handshake BFO $111 \mathrm{~Hz}$ BTO $11500 \mu \mathrm{s}$ & \\
\hline 04:41:05 (2041Z) & Ping handshake BFO $141 \mathrm{~Hz}$ BTO $11740 \mu \mathrm{s}$ & \\
\hline 05:30:00 (2130Z) & $\begin{array}{l}\text { Search and Rescue (SAR) operation activated by Kuala } \\
\text { Lumpur Rescue Coordination Centre (KL RCC) }\end{array}$ & \\
\hline 05:41:27 (2141Z) & Ping handshake BFO $168 \mathrm{~Hz}$ BTO $12780 \mu \mathrm{s}$ & \\
\hline 06:41:22 (2241Z) & Ping handshake BFO $204 \mathrm{~Hz}$ BTO $14540 \mu \mathrm{s}$ & \\
\hline 07:13:58 (2314Z) & Ground initiated Air Telephony call & Last Telephony Call ${ }^{7}$ \\
\hline 07:15:02 (2315Z) & No answer - Ping handshake BFO $216-219 \mathrm{~Hz}$ & \\
\hline 08:11:00 (0011Z) & Ping handshake BFO $252 \mathrm{~Hz}$ BTO $18040 \mu \mathrm{s}$ & Last complete Ping \\
\hline 08:19:29 (0019Z) & $\begin{array}{l}\text { Last incomplete ping requested by user BFO } 182 \mathrm{~Hz} \\
\text { BTO } 23000 \mu \mathrm{s}\end{array}$ & $\begin{array}{l}\text { Last incomplete Ping / } \\
\text { both engines out }\end{array}$ \\
\hline 08:30:00 (0030Z) & $\begin{array}{l}\text { Flight time limit based on FOB at FL } 310 \text { or above at } \\
\text { normal cruise airspeed } T A S=470 \mathrm{kts}\end{array}$ & \\
\hline 09:10:00 (0110Z) & Expected Ping handshake did not arrive & Proof of avionics out \\
\hline \multicolumn{3}{|c|}{$\begin{array}{l}\text { for technical and operational messages between aircraft and a ground communication network or a satellite } \\
\text { communication network }\end{array}$} \\
\hline \multicolumn{3}{|c|}{${ }^{2}$ ACC Subang, Malaysia } \\
\hline \multicolumn{3}{|c|}{3 ACC Ho Chi Mingh, Vietnam } \\
\hline \multicolumn{3}{|c|}{${ }^{4}$ FOB: Fuel on Board } \\
\hline \multicolumn{3}{|c|}{${ }^{5}$ XPRD: Secondary Surveillance Transponder } \\
\hline \multicolumn{3}{|c|}{${ }^{6}$ PSR: Primary Surveillance Radar (military) } \\
\hline${ }^{7}$ Not answered & out the subsequent ping proved aircraf & \\
\hline
\end{tabular}

Table 3. Key moments of the MH370 flight.

\begin{tabular}{llll}
\hline Malaysian Time & UTC & Identifier & Description \\
\hline $\mathbf{0 0 : 0 0 : 1 3}$ & $1600 \mathrm{Z}$ & $t_{\mathrm{L}}$ & Avionics power up and satellite Log on \\
$\mathbf{0 0 : 4 1 : 4 3}$ & $1642 \mathrm{Z}$ & $t_{\mathrm{T}}$ & Take-Off RWY 32R KLIA \\
$\mathbf{0 1 : 0 7 : 4 9}$ & $1708 \mathrm{Z}$ & $t_{\mathrm{A}}$ & Last Air DATA-2 ACARS message \\
$\mathbf{0 1 : 1 9 : 2 4}$ & $1719 \mathrm{Z}$ & $t_{\mathrm{C}}$ & Last COM "Good Night Malaysian Three Seven Zero" \\
$\mathbf{0 1 : 2 1 : 0 4}$ & $1721 \mathrm{Z}$ & $t_{\mathrm{X}}$ & Last XPDR fly over IGARI N06 $55^{\prime} 15^{\prime \prime}$ E103 $34^{\prime} 43^{\prime \prime}$ \\
$\mathbf{0 2 : 2 2 : 0 0}$ & $1822 \mathrm{Z}$ & $t_{\mathrm{M}}$ & Last Military PSR contact 200 NM NW of Pinang \\
$\mathbf{0 2 : 2 5 : 2 8}$ & $1825 \mathrm{Z}$ & $t_{1}$ & $\mathbf{1}^{\text {st }}$ complete satellite ping considered in the literature \\
$\boldsymbol{t}_{\mathbf{M}}+\boldsymbol{T T T}$ & $t_{\mathrm{M}}+T T T$ & $t_{\mathrm{S}}$ & Start turn on a new track \\
$\mathbf{0 3 : 4 1 : 0 3}$ & $1941 \mathrm{Z}$ & $t_{2}$ & $\mathbf{2}^{\text {nd }}$ complete satellite ping, the first on the new track \\
$\mathbf{0 4 : 4 1 : 0 5}$ & $2041 \mathrm{Z}$ & $t_{3}$ & $\mathbf{3}^{\text {rd }}$ complete satellite ping, the $2^{\text {nd }}$ on the new track \\
$\mathbf{0 5 : 4 1 : 2 7}$ & $2141 \mathrm{Z}$ & $t_{4}$ & $\mathbf{4}^{\text {th }}$ complete satellite ping, the third on the new track \\
$\mathbf{0 6 : 4 1 : 2 2}$ & $2241 \mathrm{Z}$ & $t_{5}$ & $\mathbf{5}^{\text {th }}$ complete satellite ping, the fourth on the new track \\
$\mathbf{0 8 : 1 1 : 0 0}$ & $0011 \mathrm{Z}$ & $t_{6}$ & $\mathbf{6}^{\text {th }}$ complete satellite ping, the fifth on the new track \\
$\mathbf{0 8 : 1 9 : 2 9}$ & $0019 \mathrm{Z}$ & $t_{7}=t_{\mathrm{G}}$ & $7^{\text {th }}$ incomplete user request ping - End of powered flight, \\
& & & start glide with both engines out \\
$\boldsymbol{t}_{\mathbf{G}}+T G E$ & $t_{\mathrm{G}}+T G E$ & $t_{\mathrm{E}}$ & End of flight \\
\hline
\end{tabular}

corresponds with the presumed flight level of the aircraft. This is in fact the isobaric surface for level flight, corresponding to the local meteorological data. The intersection yields a curve very close to a circle. At the given moment of the ping, the position of the aircraft is somewhere on that quasi-circle. 
The shift in carrier frequency is called BFO (Burst Frequency Offset). It is caused by the Doppler-Fizeau effect due to the relative speed between the aircraft and the satellite. In the calculations below, the BFO values were not used, and this is a major difference between this method and other methods used until now and known to the authors (Ashton et al., 2014; Hradecky, 2014). The reason for avoiding the use of $\mathrm{BFO}$ values is that the problem of relative speed is geometrically ill conditioned in this case, especially in the first half of the flight.

3. CALCULATION OF QUASI-CIRCLES. This paper models the Earth as the WGS-84 ellipsoid. The ranges define quasi-circles at the intersection between the isobaric surface that the aircraft levels on, and the sphere with the centre in the satellite antenna position and the BTO-based range as the radius.

The INMARSAT-3 satellites are five satellites in 36,000 km high geostationary orbit $\left(\mathrm{N} 0^{\circ}\right)$, as follows: AOR-W at a longitude of W54 ${ }^{\circ}, \mathrm{AOR}-\mathrm{E}$ at W15.5 $5^{\circ}, \mathrm{I}-3$ at $25^{\circ} \mathrm{E}, \mathrm{IOR}$ (the satellite used by MH370) at E64.5 $5^{\circ}$, and POR at E178 . INMARSAT-3 IOR has an orbit inclined at $1 \cdot 66^{\circ}$. This inclination gives a wobble movement with a period of $\mathrm{T}$ $=24$ hours. The actual orbital altitude of IOR at $t_{6}$ was: $35,794 \mathrm{~km}$, as compared to the target of 35,786 km Above Mean Sea Level (AMSL). Although geostationary, the actual position of the IOR satellite moved slightly during the MH370 flight.

In the Earth-Centred-Earth-Fixed (ECEF) frame, the system of equations used to calculate the seven quasi-circles (see Figure 8) are the WGS-84 rotation ellipsoid equations and the satellite-centred sphere equations:

$$
\begin{gathered}
n_{\varphi}=\frac{6378136 \cdot 6}{\sqrt{1-e_{2} \times(\sin \varphi)^{2}}} \\
\left\{\begin{array}{l}
x=\left(n_{\varphi}+H\right) \cos \varphi \cos \lambda \\
y=\left(n_{\varphi}+H\right) \cos \varphi \sin \lambda \\
z=n_{\varphi}\left(1-e_{2}\right)+H \sin \varphi
\end{array}\right. \\
\sqrt{\left(x-x_{S A T}\right)^{2}+\left(y-y_{S A T}\right)^{2}+\left(z-z_{S A T}\right)^{2}}-\text { Range }_{\text {satellite to aircraft }}=0
\end{gathered}
$$

From (Ashton et al., 2014):

$$
\begin{gathered}
\text { Range }_{\text {satellite to aircraft }}=\frac{1}{2} c \cdot(\text { BTO }- \text { bias })-\text { Range }_{\text {satellite to Perth GES }} \\
\text { bias }=-495679 \mu \mathrm{s}
\end{gathered}
$$

The Equations (2) in $x, y, z$ are substituted in Equation (3), providing a way to calculate longitude $\lambda$ as a function of latitude $\varphi$. The seven quasi-circles correspond to the seven pings, illustrated in Figure 8, which occurred at the times $t_{1}$ to $t_{7}$ (see Table 3). However, the first complete satellite ping considered in the literature was not used in this paper, because the initialisation of the problem is uncertain, so less weight should be given to the starting point. Consequently, the work presented in this paper relies on the last six quasi-circles only. As a confirmation of this selection of quasi-circles, the contribution of the six pings to the total inconsistency of the trajectory is well balanced. The individual contribution of the first ping to the total inconsistency would have been disproportionately larger than the contributions of the other pings. 
4. SOLVING TRAJECTORY EQUATIONS. The authors independently calculated the MH370 trajectory based on the following data:

1. Flight trajectory until the last known position $P \_18 \_22$ as recorded by the military primary radars ( $\mathrm{N} 6^{\circ} 36^{\prime} 15^{\prime \prime} \mathrm{E} 96^{\circ} 33^{\prime} 14^{\prime \prime}$ ) (Malaysian Gov., 2014; Hradecky, 2014).

2. The set of recorded INMARSAT (INMARSAT, 2014) satellite pings (signal handshake delays and carrier frequency drift) (Malaysian Gov., 2014, Hradecky, 2014).

3. The wind vector field, isobaric surface height and air temperature in the wider area at the moment of the flight, retrieved from the National Oceanic and Atmospheric Administration (NOAA) 2014). Interpolations in time, position, and flight levels were used for the best local current estimate of the wind velocity and the air temperature.

4. The Boeing 777-200ER flight performance and systems (Boeing, 1992a). A Boeing 777-200ER flight simulator based on a dynamic model was developed by the authors (Section 5).

5. The Boeing 777-200ER FMS (Flight Management System) specifications (Bulfer and Gifford, 1999).

6. The WGS-84 ellipsoid shape approximation of the Earth.

7. The INMARSAT-3 IOR satellite orbital data (Malaysian Gov., 2014).

The unknowns of this problem and the space of solutions are considered in the following subsections (see Figure 1).

4.1. The Time to Turn Unknown (TTT). It was assumed that the flight continued straight for a while (on the track of $291^{\circ}$ true) from the moment it vanished from the military primary radars $\left(t_{\mathbf{M}}\right.$ or $\left.\mathrm{P}_{-} 18 \_22\right)$. The duration of this straight segment TTT (Time To Turn) is one of the unknowns of the problem. TTT search domain was initially considered $0-50$ minutes, then reduced to 5-16.75 minutes, based on the following:

- In numerical search trials, for TTT over 17 minutes, the breakdown of the quadratic error $(\varepsilon)$ on the six quasi-circles starts to show an abnormal error increase for the first two quasi-circles;

- In both the uncorrected (Hradecky, 2014), and the corrected BFO diagram (Ashton et al., 2014), the turn is marked by a significant drop in the frequency due to the Doppler-Fizeau effect between the moments $1820 \mathrm{Z}$ and $1830 \mathrm{Z}$, i.e. in an 11 minutes time interval;

- The dynamic model simulation presented further provides an additional validation for the upper limitation of this time to 16.75 minutes; if the flight continued on the initial track for 17 minutes or more, the optimised trajectory solutions ( $T K$, $F L$ and $M$ ) would largely disagree with the dynamic simulation (the fuel would have been exhausted before the last complete ping due to the required thrust settings resulting from $F L$ and $M$ );

- No consistent solution emerged for TTT shorter than 5 minutes.

After TTT, a coordinated turn was simulated, using a dynamic model Boeing 777200ER simulator (see Section 5). The search step was one minute, refined down to five seconds for the promising domains. 

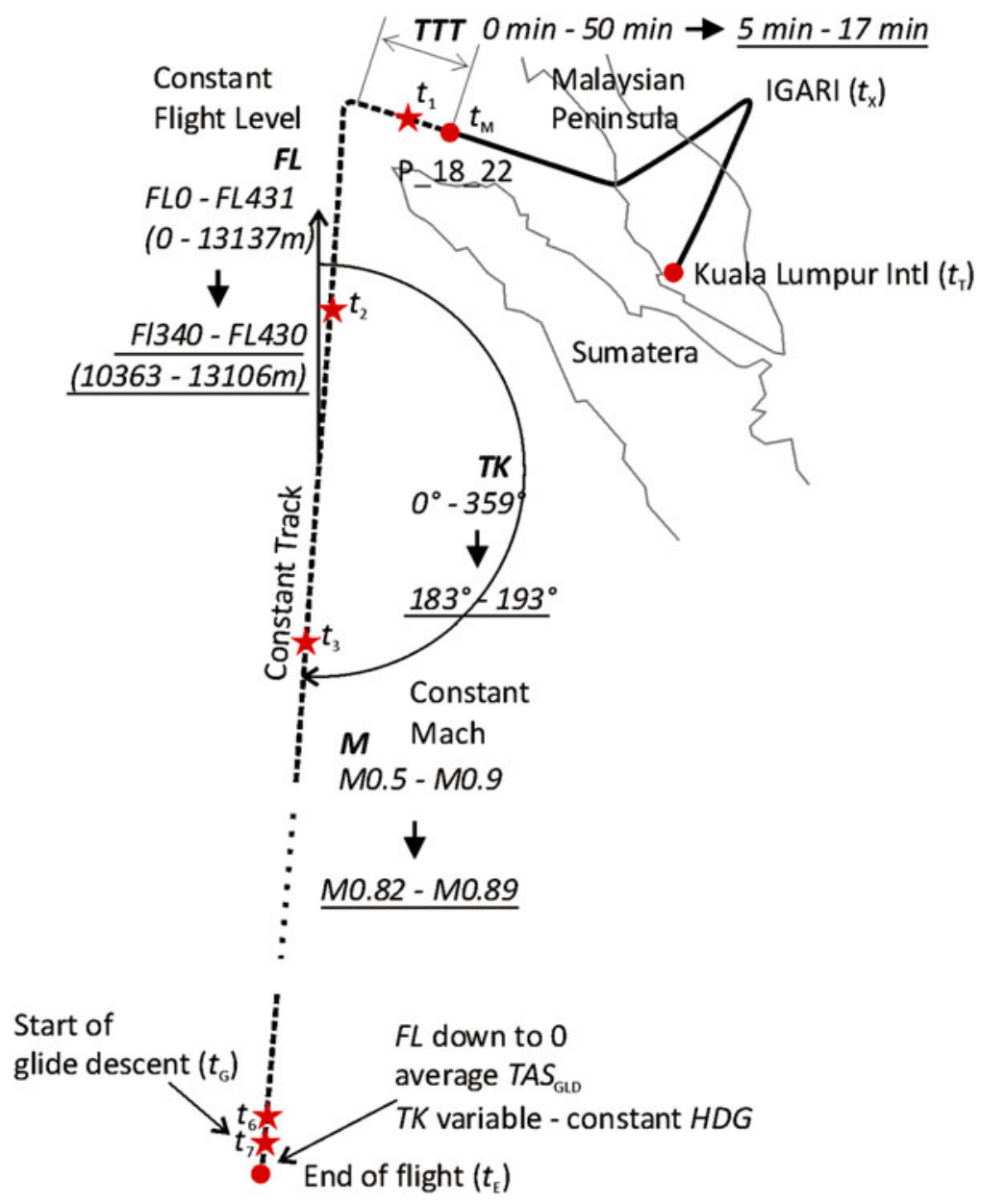

Figure 1. MH370 trajectory problem unknowns: $T T T, T K, F L$, and $M$.

This paper is based on the assumption that a single turn was made at the beginning of a long constant track segment. The BFO analysis (Figure 9 from Ashton et al., 2014) is consistent with a major turn between certain time moments: $1820 \mathrm{Z}$ and1830Z. After that turn, the $B F O$ diagram indicates a linear variation of the Doppler-Fizeau frequency shift, i.e. no other turns. A notable fact is that one $360^{\circ}$ turn at high $M$ would typically last for 11.5 minutes, and the time window in the diagram is just too small for multiple turns concentrated at the beginning of the long constant track segment. On the other hand, multiple turns sparsely distributed over the entire voyage seem impossible given the same $B F O$ diagram, because at each ping there is approximately the same $B F O$, the timing between pings is not always predictable (there are phone calls from the ground which spoil the one hour default time interval), and this is consistent with the hypothesis of an approximately constant ground speed vector. Another reason for the single turn assumption is the simplicity and the timing of the FMS programming. The programming of each additional turn into the FMS 
should have been based on ad hoc navigation points entered individually as LAT$L O N G$. Attempting such a scenario on a flight simulator indicated a significant duration of the operation, not consistent with the existing time window in this case.

One additional rationale of the single turn hypothesis comes from the speculation on the goal of the person who did program the FMS as such. The goal of this action could have been to hide evidence in a place as remote as possible. The choice of track coincides with such a strategy, to end the flight as far as possible from any populated or frequented area. Programming multiple turns into the FMS would have been pointless and detrimental to the goal of flying as far as possible. This is speculative, but it only supplements all the other non-speculative grounds of the single turn assumption.

4.2. The Track Unknown (TK). After TTT minutes, the aircraft took a turn to an unknown track $T K$ (presumed constant), and from that moment it kept that track for the entire duration of the flight, until both engines became fuel starved. This is consistent with the variation of the frequency shift due to the Doppler-Fizeau effect on the carrier (the seven $B F O$ s). Initially, all possible tracks were considered, $\left(0^{\circ}-359^{\circ}\right)$, but a refined search was performed in the promising range of $170^{\circ}-200^{\circ}$ (the Southern range), and finally in the range $183^{\circ}-193^{\circ}$, because all solutions obviously proved to be concentrated within these limits. The search step was $1^{\circ}$. The next best promising interval lays in the Northern range (around $336^{\circ}$ ) was not considered in the refined search for the following reasons:

- The Northern tracks lead to inconsistencies at least three times larger than the Southern tracks;

- In both the uncorrected (Hradecky, 2014), and the corrected BFO diagram (Ashton et al., 2014), the Southern variant matches very well the expected set of $B F O$ s, in contrast with the Northern variant.

This constant track phase of the flight (Phase 7 in Table 1) was probably flown under automated guidance, until the airplane became fuel starved, glided down and crashed. Other authors considered a constant heading for the flight. Although the Boeing 777 autopilot has a function to maintain a constant heading (HDG HOLD on the Mode Control Panel-Boeing, 1992b), it is unlikely that this flight was not under FMS guidance (LNAV mode), and in this case $H D G$ changes automatically to compensate for the crosswind. Thus, it is logical to assume a constant track flight (loxodrome or rhumb line) instead of a constant heading flight. A third hypothesis concerns a "DIRECT TO" a distant point flight, which would force navigation along the great circle (orthodrome). However, in the particular case of MH370, the difference between the orthodrome and the loxodrome routes is insignificant, and thus the constant track route covers both scenarios. A fourth hypothesis is a flight with the autopilot engaged in the "TRK HOLD" mode (constant track). This is also covered by the assumption made in this paper.

4.3. The Flight Level Unknown (FL). The flight level $(F L)$ of the cruise flight is presumed constant. Initially, all possible flight levels from $0 \mathrm{ft}$ to $43,100 \mathrm{ft}$ were considered. The problem is not very sensitive to the geometric $F L$ variable, except for the way the speed was formalised (see the Mach number below), where the temperature matters to a large extent. Also, the wind velocity changes from one level to the other, leading to significant differences between the flight levels. Very soon in the initial phase of the 
Table 4. The subspace of solutions for refined search.

\begin{tabular}{|c|c|c|c|c|c|c|}
\hline Unknown & Significance & Units & Min & Max & Step & Layers \\
\hline TTT & Time to turn & Minutes & 5 & $16 \cdot 75$ & $0 \cdot 25$ & 48 \\
\hline$T K$ & Track & $\circ$ & 183 & 193 & 1 & 11 \\
\hline$F L$ & Flight level & $\times 100$ feet & 340 & 430 & 10 & 10 \\
\hline$M$ & Mach number & - & $0 \cdot 82$ & $0 \cdot 89$ & 0.01 & 8 \\
\hline Total & & & & & & 42,240 \\
\hline
\end{tabular}

optimisation process, it became obvious that flight levels below FL340 were impossible, for two reasons:

- The inconsistency of these solutions is unacceptably high;

- The dynamic model simulation indicated that achieving a time of flight until the last half ping $\left(t_{7}\right)$ would require a lower density of air.

The fine phase of the optimisation was performed on a search range between FL340 $(34,000 \mathrm{ft})$ and FL430 (43,000 ft), with a step of 1,000 ft.

The authors found no grounds to consider a variable flight level and Mach number along the cruise. Flying under FMS guidance would require a constant flight level selected for cruise, and the same value input in the altitude selector on the Mode Control Panel (Boeing, 1992b; Bulfer and Gifford, 1999).

4.4. The Mach Number Unknown $(M)$. The Mach number $(M)$ is presumed constant. The initial search domain was between M0.65 and M0.9, but the envelope was correlated with $F L$ following the flight performance of the aircraft type. The reason for choosing Mach instead of True Airspeed (TAS), Indicated Airspeed (IAS), or Ground Speed $(G S)$ is related to the operational logic of the Flight Management System, AutoPilot and Auto-Throttle System on board the Boeing 777 aircraft. There is a slight difference in the final result between maintaining a constant $M$ and a constant $T A S$, and this comes from the outside temperature variations. The height of the isobaric surfaces, air temperatures and the wind velocity vectors along the route were taken from the NOAA archives (NOAA, 2014), as per the date and the hour of the flight. Interpolation in time, interpolation in the vertical profile of the wind vector field and interpolation in position data provide the best approximations of the real meteorological parameters. For the later stages of the optimisation, the Mach search range was reduced to M0.82-M0.89. Whereas the maximum Mach number was delivering many consistent solutions, the lower speeds proved to be constantly inconsistent and were discarded. The search step for the Mach number was $0 \cdot 01$.

4.5. Assumptions for the Last Segment of the Flight. The last incomplete user requested ping at $t_{7}$ is considered to mark the end of the powered flight, and the start of a powerless glide. The accurate simulation of the flight using a dynamic model (see Section 5) confirms this hypothesis, with a low error margin between the timing in the simulator and the timing of the ping signals (see Table 7).

The last segment of the flight was a glide with both engines out due to fuel starvation (Pleter and Constantinescu, 2014).

4.6. Trajectory Equations. Given the above considerations, the space of solutions was reduced from $34,056,000$ initial possible solutions down to 42,240 possible trajectories, as summarised in Table 4 and illustrated in Figure 1 by underlined text. 


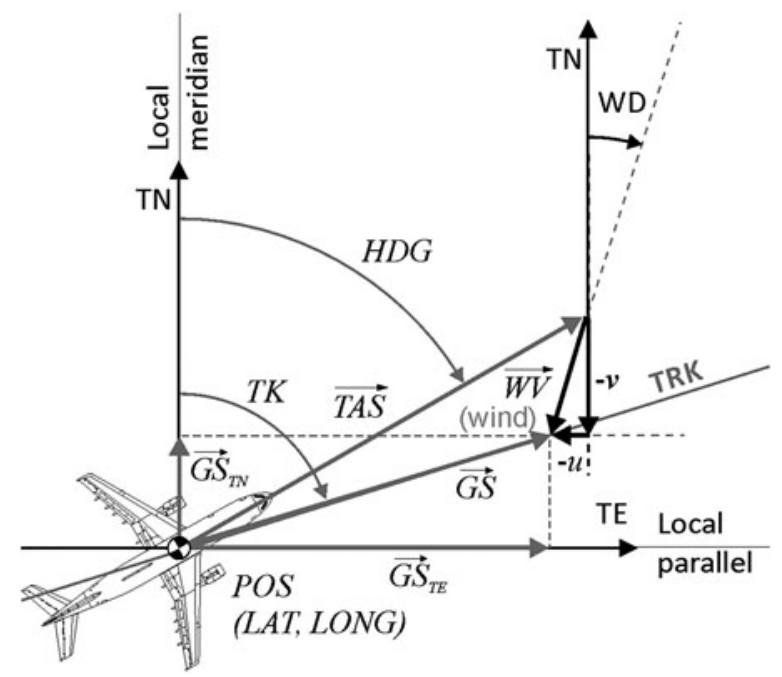

Figure 2. Local wind triangle solved at each time step in the course of flight simulation.

Considering the True North $(u)$ and the True East $(v)$ components of the local horizontal wind velocity vector retrieved from the NOAA records, the speed triangle system of trigonometric equations is the following (see Figure 2):

$$
\left\{\begin{array}{l}
T A S \cdot \cos H D G+v=G S \cdot \cos T K \\
T A S \cdot \sin H D G+u=G S \cdot \sin T K
\end{array}\right.
$$

The solution of the system is the following:

$$
\begin{gathered}
H D G=\mp 2 \tan ^{-1}\left(\frac{ \pm T A S \cdot \cos T K+\sqrt{T A S^{2}-(u \cdot \cos T K-v \cdot \sin T K)^{2}}}{u \cdot \cos T K+(T A S-v) \cdot \sin T K}\right) \\
G S=v \cdot \cos T K+u \cdot \sin T K \mp \sqrt{T A S^{2}-(u \cdot \cos T K-v \cdot \sin T K)^{2}}
\end{gathered}
$$

The system of six equations that result from the data (the time delays BTO of the six relevant pings) is over determined, and it was solved so as to minimise the quadratic sum of errors, which was considered as the inconsistency of the solution $(E)$. The inconsistency was calculated and used as an optimisation criterion to refine the search to the most plausible solution:

$$
\varepsilon=\sqrt{\sum_{1}^{6} d_{i}^{2}}=\min
$$

Each of the six errors $d_{i}$ is the distance between the aircraft at the moment of each of the six pings, and the closest point belonging to the respective quasi-circle.

The flight was simulated using a Runge-Kutta IV method with a time step of 10 seconds, integrating the local speed triangle (Figure 2) and the dynamic flight 


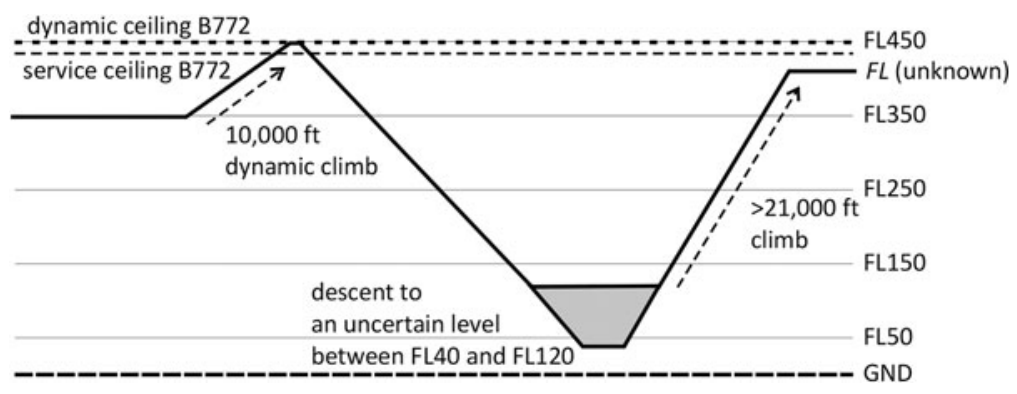

Figure 3. The flight profile of the MH370 under military primary radar surveillance.

simulator equations. At the moments of the pings, the position resulting from the simulation was compared to the position resulting from the radio transmission by calculating the distance $d_{i}$ between the two. The quadratic sum of distances $d_{i}$ was minimised using a complete search optimisation method. All calculations were done by a MATLAB application written by the authors.

The wind velocity and air temperature were retrieved from the NOAA world weather database (NOAA, 2014), with a granulation of $0.5^{\circ}$ of latitude and longitude. Linear interpolation of latitude and longitude was used between the nodes. Vertically, the data are presented for the following isobaric surfaces: 10, 20, 30, $50,70,100,150,200,250,300,350,400,450,500,550,600,650,700,750$, $800,850,900,925,950,975$, and 1000 mbar. These isobars are converted into flight levels using the ISA model, and linear interpolation was used between the isobaric surfaces.

5. THE DYNAMIC MODEL FLIGHT SIMULATOR. For the purpose of this research, a Boeing 777-200ER flight simulator was developed. The simulator is based on a dynamic model i.e. considers the mass of the aircraft and calculates the fuel flow at each time step. The simulator served three separate goals:

- To integrate the flight trajectory, the current mass of the aircraft, and the fuel consumption. By comparing the fuel consumption to the known fuel on board in the first stage of the flight, one can determine the approximate moment of fuel exhaust. This is compared to $t_{\mathrm{G}}$, which results from optimisation (see Table 7).

- To calculate the fuel consumption of a dynamic climb to FL450, a descent to FL120 or below, and a climb back to an unknown cruise FL (Figure 3). These manoeuvres were recorded by the military primary surveillance radars, so the exact levels or details of the manoeuvres are not known. Instead of a simulator based on a time step integration, the authors used a method based on energy and aircraft climb / descent efficiency to calculate the fuel consumed by it.

- To simulate the final glide descent portion, since the start of glide descent $\left(t_{\mathrm{G}}\right)$ until crash $\left(t_{\mathrm{E}}\right)$. 
Table 5. Aerodynamic Coefficients for Boeing 777 (Pereira, 2011).

\begin{tabular}{llll}
\hline $\boldsymbol{C}_{\boldsymbol{L} \boldsymbol{\alpha}}$ & $\boldsymbol{C}_{\boldsymbol{D} \mathbf{0}}$ & $\boldsymbol{\alpha}_{\boldsymbol{C L 0}}$ & $\boldsymbol{K}_{\mathbf{2}}$ \\
\hline $5 \cdot 1$ & 0.013 & $-2.8^{\circ}$ & 0.047 \\
\hline
\end{tabular}

The equations of the simulator are the following:

$$
\begin{gathered}
T A S=M \cdot a \\
C_{L}=C_{L \alpha} \cdot\left(\alpha-\alpha_{C L 0}\right) \\
C_{D}=C_{D 0}+K_{2} \cdot C_{L}^{2} \\
L=\frac{\rho_{0}}{2} \cdot T A S^{2} \cdot S \cdot C_{L} \\
D=\frac{\rho_{0}}{2} \cdot T A S^{2} \cdot S \cdot C_{D} \\
T=\frac{D}{\cos (\alpha+\tau)} \\
T \cdot \sin (\alpha+\tau)+L=m \cdot g \cdot \cos (\phi)
\end{gathered}
$$

The coefficients used for Boeing 777 are as presented in Table 5.

Simulation of the fuel consumption between the last ACARS message and last military primary radar contact was done with the following equations:

$$
\begin{gathered}
F F_{\text {avg }} \cdot\left(t_{M}-t_{A}\right)+F C_{\Delta E}=F C_{\text {total }} \\
F C_{\Delta E}=\frac{\Delta E_{p}+\Delta E_{c}}{s \cdot e f f}
\end{gathered}
$$

The efficiency eff of the engines was calibrated based on the FOB at engine start and FOB at the moment of the last ACARS message $(A)$. The taxi fuel consumption was calculated using the following formula:

$$
\frac{f}{\sqrt{T_{a m b}}}=a_{\text {taxi }}+b_{\text {taxi }} \cdot t_{\text {taxi }}+c_{\text {taxi }} \cdot n a
$$

where $a_{\text {taxi }}=-0.1223 b_{\text {taxi }}=0.0335 c_{\text {taxi }}=0.1385$ are the coefficients for a Boeing 777 , $n a$ is the number of accelerations during taxi (it is considered to be at least two) and the ambient temperature in Kuala Lumpur in March during night was assumed to be $T_{a m b}=297 \cdot 15 \mathrm{~K}$ (Khadilkar, 2011). The taxi fuel consumption which results from the above equation is $f=457.8 \mathrm{~kg}$. The remaining $\mathrm{FOB}$ at take-off is $49100-457 \cdot 8=48612 \mathrm{~kg}$. Knowing the FOB broadcast by the last ACARS message $(43,800 \mathrm{~kg})$ and considering an average fuel flow of $F F_{\text {avg }}=6406 \mathrm{~kg} / \mathrm{h}$ and the specific energy of Jet A-1, $s=43.02 \mathrm{MJ} / \mathrm{kg}$, the resultant efficiency of the engines is $32 \cdot 32 \%$. In this case, both the kinematic and the potential energy of the aircraft change. Using the calibrated engine efficiency, the resulting fuel consumption between the last ACARS message $(A)$ and last military primary surveillance radar contact $(M)$ is approximately $10,000 \mathrm{~kg}$, depending on the $F L$ to which the aircraft is considered to have climbed for the long cruise flight towards the south. For example, if the aircraft climbs to FL390, the calculated fuel consumption for the 
Table 6. Equation (20) Coefficients.

\begin{tabular}{lll}
\hline$p_{0,0}$ & $p_{1,0}$ & $p_{0,1}$ \\
\hline $31 \cdot 47$ & $0 \cdot 004923$ & $0 \cdot 01895$ \\
\hline
\end{tabular}

last ACARS - last primary radar contact segment is $F C_{\text {total }}=10065 \cdot 3 \mathrm{~kg}$. In this case only the change in potential energy is considered (calculated with an average mass) and only at the climb regions. It is supposed that the fuel economy during the descending portions of the flight is balanced by the higher consumption in the dense air.

Simulation of fuel flow during the long cruise flight is based on Boeing (1992a) and Filippone (2006). Using the calculated thrust and the mass of the aircraft, the following polynomial equation was defined (coefficients are given in Table 6):

$$
F F / E N G=p_{0,0}+p_{1,0} \cdot m+p_{0,1} \cdot T
$$

Simulation of the final glide descent with both engines out in the time interval TGD presumed 9 minutes is presented in Pleter and Constantinescu (2014).

During the cruise flight, $T K$ is kept constant by small turns, which compensate for crosswind. However, in the glide descent region, the simulation keeps a constant $H D G$ instead of $T K$, and these turns are no longer performed, as illustrated in the inset in Figure 8. This is consistent with the expected behaviour of the automated systems. By keeping a constant $H D G$, the local crosswind slightly drifted the aircraft during the gliding descent.

6. ANALYSIS OF RESULTS. The multimodal optimisation using $\varepsilon$ as a criterion (inconsistency to be minimised) yields the most probable trajectories and the most probable values of the unknowns $T T T, T K$, and $M$. The unknown $F L$ is considered a parameter, because the problem is not sensitive with respect to the geometric $F L$. Just two $T K$ ranges came out to be consistent: the Southern track around $190^{\circ}$ (true) and the Northern track of around $336^{\circ}$. The Southern track fits better (a very low inconsistency, 38 solutions between 16 and $25 \mathrm{~km}$ ), whereas the Northern track does not fit so well (zero solutions under $30 \mathrm{~km}$ ).

The multimodal optimisation yields the set of all solutions with a certain minimum probability instead of a single most probable solution. Given the nature of the problem and the scarcity of data coming from a unique source, this approach adds more value than the initial search done by the same authors for the most probable trajectory (Pleter and Constantinescu, 2014). Thus all trajectories with an overall inconsistency lower than $25 \mathrm{~km}$ were considered as potential solutions, and they are represented in Tables 7 and 8, and in Figures 4 to 6 . The threshold of $25 \mathrm{~km}$ is remarkably low as compared to the total length of the trajectory (almost 6,000 km). There are 38 consistent solutions (with $\varepsilon \leqslant 25 \mathrm{~km}$ ), and they are analysed in Table 7 and in the subsequent Figures. In Figure 4 all the 38 consistent solutions were represented as cylinders. The diameter of the cylinder is the inverse function of the inconsistency, i.e. consistency $(1 / \varepsilon)$.

The most consistent solutions presented in Table 7 have a remarkably low inconsistency, of $\varepsilon<17 \mathrm{~km}$. Column "Fuel error" in Table 7 (second part) compares the top of descent $\left(t_{\mathrm{G}}\right)$ calculated with the optimisation method based on the satellite pings and 
Table 7. Consistent MH370 trajectory solutions and the corresponding positions of the end of flight (E) - solutions in yellow are confirmed by the available fuel criterion, with a fuel error $\leq 1 \%$.

\begin{tabular}{|c|c|c|c|c|c|c|c|c|c|c|c|c|c|c|c|c|c|}
\hline Solution & $\begin{array}{l}\varepsilon \\
(\mathrm{km})\end{array}$ & $\begin{array}{l}T T T \\
(\mathrm{~min})\end{array}$ & $\begin{array}{l}T K \\
\left(^{\circ}\right)\end{array}$ & $\begin{array}{l}M \\
(-)\end{array}$ & $\begin{array}{l}F L \\
(\mathrm{ft})\end{array}$ & $\begin{array}{l}L A T_{2} \\
\left(^{\circ}\right)\end{array}$ & $\begin{array}{l}\operatorname{LONG}_{2} \\
\left(^{\circ}\right)\end{array}$ & $\begin{array}{l}G S_{2} \\
\text { (kts) }\end{array}$ & $\begin{array}{l}L A T_{3} \\
\left(^{\circ}\right)\end{array}$ & $\begin{array}{l}\mathrm{LONG}_{3} \\
\left(^{\circ}\right)\end{array}$ & $\begin{array}{l}G S_{3} \\
\text { (kts) }\end{array}$ & $\begin{array}{l}L A T_{4} \\
\left(^{\circ}\right)\end{array}$ & $\begin{array}{l}\mathrm{LONG}_{4} \\
\left(^{\circ}\right)\end{array}$ & $\begin{array}{l}G S_{4} \\
\text { (kts) }\end{array}$ & $\begin{array}{l}L A T_{5} \\
\left({ }^{\circ}\right)\end{array}$ & $\begin{array}{l}L O N G_{5} \\
\left(^{\circ}\right)\end{array}$ & $\begin{array}{l}G S_{5} \\
(\mathrm{kts})\end{array}$ \\
\hline 1 & $24 \cdot 9$ & $7: 10$ & 191 & $0 \cdot 87$ & 38,000 & $-2 \cdot 58$ & $93 \cdot 51$ & $501 \cdot 9$ & $-10 \cdot 79$ & $91 \cdot 88$ & $508 \cdot 1$ & $-19 \cdot 13$ & $90 \cdot 22$ & $493 \cdot 5$ & $-27 \cdot 00$ & $88 \cdot 48$ & $469 \cdot 8$ \\
\hline 2 & $23 \cdot 3$ & $7: 25$ & 191 & $0 \cdot 86$ & 36,000 & $-2 \cdot 59$ & 93.49 & $503 \cdot 3$ & $-10 \cdot 80$ & $91 \cdot 86$ & $506 \cdot 5$ & $-19 \cdot 14$ & $90 \cdot 19$ & $499 \cdot 6$ & $-27 \cdot 02$ & $88 \cdot 46$ & $470 \cdot 2$ \\
\hline 3 & $22 \cdot 3$ & $7: 40$ & 191 & $0 \cdot 85$ & 34,000 & $-2 \cdot 61$ & 93.47 & $505 \cdot 1$ & $-10 \cdot 81$ & $91 \cdot 83$ & $505 \cdot 1$ & $-19 \cdot 16$ & $90 \cdot 17$ & $505 \cdot 9$ & $-27 \cdot 06$ & 88.43 & $471 \cdot 1$ \\
\hline 4 & $24 \cdot 3$ & $8: 00$ & 190 & $0 \cdot 88$ & 42,000 & $-2 \cdot 25$ & $93 \cdot 61$ & $492 \cdot 6$ & $-10 \cdot 33$ & $92 \cdot 15$ & $499 \cdot 0$ & $-18 \cdot 57$ & $90 \cdot 65$ & 493.9 & $-26 \cdot 46$ & $89 \cdot 10$ & $468 \cdot 3$ \\
\hline 5 & $24 \cdot 3$ & $8: 05$ & 190 & $0 \cdot 87$ & 40,000 & $-2 \cdot 28$ & 93.61 & $494 \cdot 2$ & $-10 \cdot 39$ & $92 \cdot 15$ & $500 \cdot 9$ & $-18 \cdot 65$ & $90 \cdot 65$ & $490 \cdot 9$ & $-26 \cdot 50$ & $89 \cdot 10$ & $465 \cdot 7$ \\
\hline 6 & $19 \cdot 8$ & $8: 40$ & 190 & $0 \cdot 87$ & 39,000 & $-2 \cdot 24$ & $93 \cdot 54$ & $498 \cdot 3$ & $-10 \cdot 42$ & $92 \cdot 06$ & $505 \cdot 2$ & $-18 \cdot 75$ & $90 \cdot 56$ & $491 \cdot 7$ & $-26 \cdot 61$ & 88.99 & $467 \cdot 5$ \\
\hline 7 & $17 \cdot 9$ & $8: 50$ & 190 & $0 \cdot 86$ & 37,000 & $-2 \cdot 27$ & $93 \cdot 52$ & $499 \cdot 2$ & $-10 \cdot 45$ & $92 \cdot 05$ & $503 \cdot 7$ & $-18 \cdot 77$ & $90 \cdot 55$ & $495 \cdot 4$ & $-26 \cdot 64$ & 88.98 & $467 \cdot 6$ \\
\hline 8 & $16 \cdot 4$ & $9: 05$ & 190 & $0 \cdot 85$ & 35,000 & $-2 \cdot 28$ & $93 \cdot 50$ & $500 \cdot 4$ & $-10 \cdot 46$ & $92 \cdot 02$ & $501 \cdot 7$ & $-18 \cdot 78$ & $90 \cdot 52$ & $500 \cdot 9$ & $-26 \cdot 67$ & 88.95 & $468 \cdot 4$ \\
\hline 9 & $21 \cdot 5$ & $9: 30$ & 189 & $0 \cdot 88$ & 43,000 & -1.92 & 93.63 & $489 \cdot 6$ & $-9 \cdot 95$ & $92 \cdot 31$ & $495 \cdot 0$ & $-18 \cdot 14$ & $90 \cdot 97$ & $494 \cdot 7$ & $-26 \cdot 06$ & 89.59 & $467 \cdot 8$ \\
\hline 10 & $21 \cdot 5$ & $9: 35$ & 189 & $0 \cdot 87$ & 41,000 & -1.94 & 93.63 & $490 \cdot 8$ & $-10 \cdot 01$ & $92 \cdot 32$ & $496 \cdot 6$ & $-18 \cdot 23$ & $90 \cdot 98$ & $492 \cdot 6$ & $-26 \cdot 09$ & $89 \cdot 59$ & $465 \cdot 1$ \\
\hline 11 & $23 \cdot 9$ & $10: 05$ & 189 & $0 \cdot 88$ & 42,000 & $-1 \cdot 88$ & $93 \cdot 56$ & $493 \cdot 4$ & $-9 \cdot 98$ & $92 \cdot 24$ & $498 \cdot 9$ & $-18 \cdot 23$ & $90 \cdot 89$ & $496 \cdot 3$ & $-26 \cdot 17$ & $89 \cdot 49$ & $469 \cdot 3$ \\
\hline 12 & $17 \cdot 6$ & $10: 10$ & 189 & 0.87 & 40,000 & $-1 \cdot 88$ & $93 \cdot 54$ & $494 \cdot 7$ & $-10 \cdot 02$ & $92 \cdot 22$ & $500 \cdot 8$ & $-18 \cdot 30$ & $90 \cdot 88$ & $494 \cdot 0$ & $-26 \cdot 19$ & $89 \cdot 48$ & $466 \cdot 7$ \\
\hline 13 & $16 \cdot 2$ & $10: 25$ & 189 & $0 \cdot 86$ & 38,000 & -1.91 & $93 \cdot 53$ & $495 \cdot 9$ & $-10 \cdot 06$ & $92 \cdot 21$ & $501 \cdot 3$ & $-18 \cdot 36$ & $90 \cdot 87$ & $493 \cdot 8$ & $-26 \cdot 23$ & $89 \cdot 47$ & $465 \cdot 4$ \\
\hline 14 & $14 \cdot 9$ & $10: 35$ & 189 & $0 \cdot 85$ & 36,000 & -1.94 & $93 \cdot 52$ & $496 \cdot 3$ & $-10 \cdot 09$ & $92 \cdot 20$ & $499 \cdot 0$ & $-18 \cdot 38$ & $90 \cdot 85$ & $497 \cdot 3$ & $-26 \cdot 26$ & $89 \cdot 45$ & $466 \cdot 4$ \\
\hline 15 & $13 \cdot 9$ & $10: 50$ & 189 & $0 \cdot 84$ & 34,000 & -1.96 & 93.49 & $497 \cdot 2$ & $-10 \cdot 12$ & $92 \cdot 17$ & $496 \cdot 9$ & $-18 \cdot 40$ & $90 \cdot 82$ & $501 \cdot 1$ & $-26 \cdot 30$ & $89 \cdot 42$ & $467 \cdot 8$ \\
\hline 16 & $22 \cdot 0$ & $10: 55$ & 188 & $0 \cdot 87$ & 42,000 & $-1 \cdot 64$ & 93.66 & $487 \cdot 4$ & $-9 \cdot 65$ & $92 \cdot 50$ & $492 \cdot 4$ & $-17 \cdot 82$ & $91 \cdot 31$ & $491 \cdot 9$ & $-25 \cdot 70$ & $90 \cdot 09$ & $465 \cdot 6$ \\
\hline 17 & $24 \cdot 7$ & $11: 00$ & 189 & $0 \cdot 86$ & 37,000 & $-1 \cdot 88$ & 93.45 & $499 \cdot 2$ & $-10 \cdot 08$ & $92 \cdot 12$ & $503 \cdot 3$ & $-18 \cdot 42$ & $90 \cdot 77$ & $498 \cdot 0$ & $-26 \cdot 34$ & $89 \cdot 36$ & $468 \cdot 7$ \\
\hline 18 & $19 \cdot 7$ & $11: 10$ & 188 & $0 \cdot 87$ & 42,000 & $-1 \cdot 59$ & 93.63 & $487 \cdot 6$ & $-9 \cdot 61$ & $92 \cdot 47$ & $492 \cdot 6$ & $-17 \cdot 77$ & $91 \cdot 29$ & $492 \cdot 0$ & $-25 \cdot 66$ & $90 \cdot 06$ & $466 \cdot 0$ \\
\hline 19 & $24 \cdot 5$ & $11: 30$ & 188 & $0 \cdot 88$ & 43,000 & $-1 \cdot 55$ & $93 \cdot 57$ & $490 \cdot 2$ & $-9 \cdot 61$ & $92 \cdot 40$ & $494 \cdot 8$ & $-17 \cdot 81$ & $91 \cdot 21$ & $495 \cdot 3$ & $-25 \cdot 77$ & 89.98 & $469 \cdot 6$ \\
\hline 20 & $17 \cdot 1$ & $11: 45$ & 188 & $0 \cdot 87$ & 41,000 & $-1 \cdot 55$ & $93 \cdot 55$ & $491 \cdot 4$ & $-9 \cdot 63$ & $92 \cdot 39$ & $496 \cdot 7$ & $-17 \cdot 86$ & $91 \cdot 20$ & $494 \cdot 6$ & $-25 \cdot 77$ & 89.96 & $467 \cdot 0$ \\
\hline 21 & $17 \cdot 0$ & $11: 55$ & 188 & $0 \cdot 86$ & 39,000 & -1.57 & $93 \cdot 55$ & $492 \cdot 8$ & $-9 \cdot 69$ & $92 \cdot 38$ & $498 \cdot 9$ & $-17 \cdot 96$ & $91 \cdot 19$ & $493 \cdot 5$ & $-25 \cdot 82$ & 89.95 & $464 \cdot 2$ \\
\hline 22 & $17 \cdot 0$ & $12: 05$ & 188 & $0 \cdot 85$ & 37,000 & $-1 \cdot 60$ & $93 \cdot 53$ & $493 \cdot 0$ & $-9 \cdot 72$ & $92 \cdot 36$ & $496 \cdot 9$ & $-17 \cdot 98$ & $91 \cdot 18$ & $495 \cdot 1$ & $-25 \cdot 85$ & 89.94 & $464 \cdot 4$ \\
\hline 23 & $16 \cdot 1$ & $12: 10$ & 188 & $0 \cdot 84$ & 35,000 & $-1 \cdot 63$ & $93 \cdot 51$ & $493 \cdot 3$ & $-9 \cdot 74$ & $92 \cdot 34$ & $494 \cdot 2$ & -17.99 & $91 \cdot 15$ & $497 \cdot 6$ & $-25 \cdot 88$ & 89.91 & $465 \cdot 3$ \\
\hline 24 & $23 \cdot 5$ & $12: 30$ & 188 & $0 \cdot 86$ & 38,000 & $-1 \cdot 53$ & 93.46 & $496 \cdot 1$ & $-9 \cdot 70$ & $92 \cdot 28$ & $501 \cdot 3$ & $-18 \cdot 02$ & $91 \cdot 09$ & $496 \cdot 7$ & $-25 \cdot 92$ & $89 \cdot 84$ & $466 \cdot 7$ \\
\hline
\end{tabular}




\begin{tabular}{|c|c|c|c|c|c|c|c|c|c|c|c|c|c|c|c|c|c|}
\hline 25 & $18 \cdot 0$ & $12: 40$ & 187 & $0 \cdot 87$ & 43,000 & $-1 \cdot 25$ & 93.63 & $484 \cdot 4$ & $-9 \cdot 22$ & $92 \cdot 62$ & $488 \cdot 1$ & $-17 \cdot 33$ & $91 \cdot 59$ & $489 \cdot 2$ & $-25 \cdot 24$ & $90 \cdot 53$ & $467 \cdot 9$ \\
\hline 26 & $23 \cdot 6$ & $12: 40$ & 188 & $0 \cdot 85$ & 36,000 & $-1 \cdot 55$ & $93 \cdot 43$ & $496 \cdot 2$ & $-9 \cdot 72$ & $92 \cdot 26$ & $498 \cdot 5$ & $-18 \cdot 03$ & $91 \cdot 07$ & $499 \cdot 1$ & $-25 \cdot 95$ & $89 \cdot 82$ & $467 \cdot 6$ \\
\hline 27 & $24 \cdot 2$ & $12: 45$ & 187 & $0 \cdot 86$ & 41,000 & $-1 \cdot 28$ & 93.63 & $485 \cdot 5$ & $-9 \cdot 27$ & $92 \cdot 62$ & $490 \cdot 5$ & $-17 \cdot 42$ & $91 \cdot 60$ & $489 \cdot 7$ & $-25 \cdot 28$ & $90 \cdot 53$ & $464 \cdot 1$ \\
\hline 28 & $17 \cdot 1$ & $13: 15$ & 187 & $0 \cdot 87$ & 42,000 & $-1 \cdot 21$ & $93 \cdot 56$ & $488 \cdot 2$ & $-9 \cdot 24$ & $92 \cdot 54$ & $492 \cdot 5$ & $-17 \cdot 42$ & $91 \cdot 50$ & $492 \cdot 4$ & $-25 \cdot 35$ & $90 \cdot 43$ & $468 \cdot 5$ \\
\hline 29 & $17 \cdot 8$ & $13: 25$ & 187 & $0 \cdot 86$ & 40,000 & $-1 \cdot 23$ & $93 \cdot 55$ & $489 \cdot 4$ & $-9 \cdot 29$ & $92 \cdot 53$ & $495 \cdot 0$ & $-17 \cdot 51$ & $91 \cdot 50$ & $492 \cdot 7$ & $-25 \cdot 39$ & $90 \cdot 42$ & $465 \cdot 0$ \\
\hline 30 & $21 \cdot 5$ & $13: 35$ & 187 & $0 \cdot 85$ & 38,000 & $-1 \cdot 26$ & $93 \cdot 54$ & $490 \cdot 1$ & $-9 \cdot 34$ & $92 \cdot 52$ & $495 \cdot 6$ & $-17 \cdot 58$ & $91 \cdot 49$ & $493 \cdot 0$ & $-25 \cdot 43$ & $90 \cdot 41$ & $462 \cdot 9$ \\
\hline 31 & $21 \cdot 6$ & $13: 40$ & 187 & $0 \cdot 84$ & 36,000 & $-1 \cdot 30$ & $93 \cdot 52$ & $489 \cdot 9$ & $-9 \cdot 38$ & $92 \cdot 51$ & $492 \cdot 5$ & $-17 \cdot 60$ & $91 \cdot 48$ & $493 \cdot 7$ & $-25 \cdot 47$ & $90 \cdot 40$ & $463 \cdot 3$ \\
\hline 32 & $22 \cdot 0$ & $13: 50$ & 187 & $0 \cdot 83$ & 34,000 & $-1 \cdot 34$ & $93 \cdot 50$ & $490 \cdot 2$ & $-9 \cdot 43$ & $92 \cdot 49$ & $489 \cdot 7$ & $-17 \cdot 63$ & $91 \cdot 45$ & 494.9 & $-25 \cdot 53$ & $90 \cdot 38$ & $464 \cdot 3$ \\
\hline 33 & $23 \cdot 9$ & $14: 00$ & 187 & $0 \cdot 86$ & 39,000 & $-1 \cdot 20$ & $93 \cdot 47$ & $493 \cdot 2$ & $-9 \cdot 33$ & $92 \cdot 45$ & $499 \cdot 4$ & $-17 \cdot 61$ & $91 \cdot 41$ & $495 \cdot 4$ & $-25 \cdot 52$ & $90 \cdot 32$ & $465 \cdot 9$ \\
\hline 34 & $20 \cdot 7$ & $14: 45$ & 186 & $0 \cdot 87$ & 43,000 & $-0 \cdot 86$ & $93 \cdot 55$ & $485 \cdot 0$ & $-8 \cdot 85$ & 92.68 & $487 \cdot 6$ & $-16 \cdot 97$ & $91 \cdot 80$ & $489 \cdot 3$ & $-24 \cdot 91$ & $90 \cdot 89$ & $470 \cdot 2$ \\
\hline 35 & $19 \cdot 4$ & $14: 55$ & 186 & $0 \cdot 86$ & 41,000 & $-0 \cdot 89$ & $93 \cdot 54$ & $485 \cdot 9$ & $-8 \cdot 90$ & $92 \cdot 68$ & $490 \cdot 4$ & $-17 \cdot 05$ & $91 \cdot 80$ & $490 \cdot 6$ & $-24 \cdot 95$ & $90 \cdot 88$ & $466 \cdot 1$ \\
\hline 36 & $24 \cdot 6$ & $15: 05$ & 186 & $0 \cdot 85$ & 39,000 & -0.92 & $93 \cdot 54$ & $487 \cdot 2$ & $-8 \cdot 96$ & 92.67 & 493.9 & $-17 \cdot 16$ & $91 \cdot 80$ & 491.9 & $-25 \cdot 01$ & $90 \cdot 88$ & $461 \cdot 7$ \\
\hline 37 & $23 \cdot 6$ & $15: 45$ & 185 & $0 \cdot 86$ & 43,000 & -0.59 & $93 \cdot 62$ & $478 \cdot 9$ & $-8 \cdot 49$ & $92 \cdot 90$ & $480 \cdot 7$ & $-16 \cdot 51$ & $92 \cdot 17$ & $484 \cdot 5$ & $-24 \cdot 39$ & $91 \cdot 43$ & $467 \cdot 2$ \\
\hline 38 & $22 \cdot 5$ & $16: 20$ & 185 & $0 \cdot 86$ & 42,000 & -0.56 & $93 \cdot 54$ & $482 \cdot 4$ & $-8 \cdot 52$ & $92 \cdot 82$ & $484 \cdot 8$ & $-16 \cdot 61$ & $92 \cdot 09$ & $487 \cdot 8$ & $-24 \cdot 51$ & $91 \cdot 34$ & $467 \cdot 4$ \\
\hline
\end{tabular}

\begin{tabular}{|c|c|c|c|c|c|c|c|c|c|c|c|c|c|c|c|c|}
\hline Solution & $\begin{array}{l}\varepsilon \\
(\mathrm{km})\end{array}$ & $\begin{array}{l}T T T \\
(\mathrm{~min})\end{array}$ & $\begin{array}{l}T K \\
\left({ }^{\circ}\right)\end{array}$ & $\begin{array}{l}M \\
(-)\end{array}$ & $\begin{array}{l}F L \\
(\mathrm{ft})\end{array}$ & $\begin{array}{l}L A T_{6} \\
\left(^{\circ}\right)\end{array}$ & $\begin{array}{l}L O N G_{6} \\
\left(^{\circ}\right)\end{array}$ & $\begin{array}{l}G S_{6} \\
(\mathrm{kts})\end{array}$ & $\begin{array}{l}L A T_{7} \\
\left(^{\circ}\right)\end{array}$ & $\begin{array}{l}\mathrm{LONG}_{7} \\
\left(^{\circ}\right)\end{array}$ & $\begin{array}{l}G S_{7} \\
\text { (kts) }\end{array}$ & $\begin{array}{l}L A T_{E} \\
\left(^{\circ}\right)\end{array}$ & $\begin{array}{l}L O N G_{E} \\
\left(^{\circ}\right)\end{array}$ & $\begin{array}{l}\text { Fuel Erro } \\
(\%)\end{array}$ & (sec) & $\begin{array}{l}\varepsilon^{*} \text { wlo wind } \\
(\mathrm{km}\end{array}$ \\
\hline 1 & $24 \cdot 9$ & $7: 10$ & 191 & $0 \cdot 87$ & 38,000 & $-38 \cdot 57$ & $85 \cdot 64$ & $478 \cdot 4$ & $-39 \cdot 66$ & $85 \cdot 34$ & $475 \cdot 1$ & $-40 \cdot 42$ & $85 \cdot 14$ & $-2 \cdot 6 \%$ & -681 & $195 \cdot 8$ \\
\hline 2 & $23 \cdot 3$ & $7: 25$ & 191 & $0 \cdot 86$ & 36,000 & $-38 \cdot 54$ & 85.63 & $479 \cdot 0$ & $-39 \cdot 64$ & $85 \cdot 34$ & $474 \cdot 0$ & $-40 \cdot 40$ & $85 \cdot 14$ & $-4 \cdot 6 \%$ & -1186 & $174 \cdot 3$ \\
\hline 3 & $22 \cdot 3$ & $7: 40$ & 191 & $0 \cdot 85$ & 34,000 & $-38 \cdot 55$ & $85 \cdot 62$ & $480 \cdot 0$ & $-39 \cdot 64$ & $85 \cdot 34$ & $473 \cdot 2$ & $-40 \cdot 41$ & $85 \cdot 15$ & $-7 \cdot 2 \%$ & -1859 & $154 \cdot 6$ \\
\hline 4 & $24 \cdot 3$ & $8: 00$ & 190 & $0 \cdot 88$ & 42,000 & $-38 \cdot 09$ & $86 \cdot 52$ & $477 \cdot 5$ & $-39 \cdot 18$ & $86 \cdot 25$ & $474 \cdot 8$ & $-39 \cdot 94$ & $86 \cdot 07$ & $1 \cdot 0 \%$ & 251 & $188 \cdot 9$ \\
\hline 5 & $24 \cdot 3$ & $8: 05$ & 190 & 0.87 & 40,000 & $-38 \cdot 02$ & $86 \cdot 53$ & $475 \cdot 4$ & $-39 \cdot 12$ & $86 \cdot 26$ & $472 \cdot 1$ & $-39 \cdot 88$ & 86.08 & $-0 \cdot 4 \%$ & -95 & $187 \cdot 0$ \\
\hline 6 & $19 \cdot 8$ & $8: 40$ & 190 & $0 \cdot 87$ & 39,000 & $-38 \cdot 17$ & $86 \cdot 41$ & $476 \cdot 8$ & $-39 \cdot 26$ & $86 \cdot 14$ & $473 \cdot 6$ & $-40 \cdot 02$ & $85 \cdot 96$ & $-1 \cdot 5 \%$ & -392 & $194 \cdot 7$ \\
\hline 7 & $17 \cdot 9$ & $8: 50$ & 190 & $0 \cdot 86$ & 37,000 & $-38 \cdot 14$ & $86 \cdot 41$ & $476 \cdot 5$ & $-39 \cdot 24$ & $86 \cdot 15$ & $472 \cdot 8$ & $-40 \cdot 00$ & 85.97 & $-3 \cdot 2 \%$ & -836 & $178 \cdot 4$ \\
\hline 8 & $16 \cdot 4$ & $9: 05$ & 190 & $0 \cdot 85$ & 35,000 & $-38 \cdot 14$ & $86 \cdot 40$ & $477 \cdot 0$ & $-39 \cdot 23$ & $86 \cdot 14$ & $472 \cdot 7$ & $-40 \cdot 00$ & 85.97 & $-5 \cdot 5 \%$ & -1418 & $163 \cdot 5$ \\
\hline 9 & $21 \cdot 5$ & $9: 30$ & 189 & $0 \cdot 88$ & 43,000 & $-37 \cdot 70$ & $87 \cdot 28$ & $476 \cdot 8$ & $-38 \cdot 80$ & $87 \cdot 04$ & $474 \cdot 3$ & $-39 \cdot 56$ & $86 \cdot 88$ & $1 \cdot 6 \%$ & 424 & $190 \cdot 1$ \\
\hline 10 & $21 \cdot 5$ & $9: 35$ & 189 & $0 \cdot 87$ & 41,000 & $-37 \cdot 63$ & $87 \cdot 29$ & 474.9 & $-38 \cdot 73$ & $87 \cdot 05$ & $471 \cdot 6$ & $-39 \cdot 49$ & $86 \cdot 88$ & $0 \cdot 6 \%$ & 151 & $186 \cdot 7$ \\
\hline 11 & $23 \cdot 9$ & $10: 05$ & 189 & $0 \cdot 88$ & 42,000 & $-37 \cdot 83$ & $87 \cdot 17$ & $478 \cdot 3$ & $-38 \cdot 94$ & 86.93 & $475 \cdot 4$ & $-39 \cdot 70$ & $86 \cdot 77$ & $1 \cdot 0 \%$ & 253 & $200 \cdot 8$ \\
\hline 12 & $17 \cdot 6$ & $10: 10$ & 189 & $0 \cdot 87$ & 40,000 & $-37 \cdot 75$ & $87 \cdot 17$ & $476 \cdot 5$ & $-38 \cdot 85$ & 86.93 & $472 \cdot 8$ & $-39 \cdot 62$ & $86 \cdot 76$ & $-0 \cdot 4 \%$ & -95 & $263 \cdot 9$ \\
\hline 13 & $16 \cdot 2$ & $10: 25$ & 189 & $0 \cdot 86$ & 38,000 & $-37 \cdot 71$ & $87 \cdot 16$ & $475 \cdot 3$ & $-38 \cdot 81$ & 86.93 & $471 \cdot 1$ & $-39 \cdot 57$ & $86 \cdot 76$ & $-2 \cdot 1 \%$ & -533 & $181 \cdot 0$ \\
\hline 14 & $14 \cdot 9$ & $10: 35$ & 189 & $0 \cdot 85$ & 36,000 & $-37 \cdot 71$ & $87 \cdot 16$ & $474 \cdot 7$ & $-38 \cdot 80$ & 86.93 & $470 \cdot 8$ & $-39 \cdot 57$ & $86 \cdot 77$ & $-4 \cdot 0 \%$ & -1028 & $164 \cdot 9$ \\
\hline
\end{tabular}


Table 7. (Continued)

\begin{tabular}{|c|c|c|c|c|c|c|c|c|c|c|c|c|c|c|c|c|}
\hline Solution & $\begin{array}{l}\varepsilon \\
(\mathrm{km})\end{array}$ & $\begin{array}{l}T T T \\
(\mathrm{~min})\end{array}$ & $\begin{array}{l}T K \\
\left({ }^{\circ}\right)\end{array}$ & $\begin{array}{l}M \\
(-)\end{array}$ & $\begin{array}{l}F L \\
(\mathrm{ft})\end{array}$ & $\begin{array}{l}L A T_{6} \\
\left({ }^{\circ}\right)\end{array}$ & $\begin{array}{l}L^{L O N G_{6}} \\
\left({ }^{\circ}\right)\end{array}$ & $\begin{array}{l}G S_{6} \\
\text { (kts) }\end{array}$ & $\begin{array}{l}L A T_{7} \\
\left({ }^{\circ}\right)\end{array}$ & $\begin{array}{l}L^{L O N G_{7}} \\
\left({ }^{\circ}\right)\end{array}$ & $\begin{array}{l}G S_{7} \\
\text { (kts) }\end{array}$ & $\begin{array}{l}L A T_{E} \\
\left({ }^{\circ}\right)\end{array}$ & $\begin{array}{l}L O N G_{E} \\
\left({ }^{\circ}\right)\end{array}$ & $\begin{array}{l}\text { Fuel Erro } \\
(\%)\end{array}$ & $\begin{array}{l}r \\
(\mathrm{sec})\end{array}$ & $\begin{array}{l}\varepsilon^{*} \text { wlo wind } \\
(\mathrm{km}\end{array}$ \\
\hline 15 & $13 \cdot 9$ & $10: 50$ & 189 & $0 \cdot 84$ & 34,000 & $-37 \cdot 72$ & $87 \cdot 14$ & $474 \cdot 6$ & $-38 \cdot 82$ & $86 \cdot 92$ & $470 \cdot 9$ & $-39 \cdot 58$ & $86 \cdot 76$ & $-6 \cdot 5 \%$ & -1688 & $144 \cdot 7$ \\
\hline 16 & $22 \cdot 0$ & $10: 55$ & 188 & $0 \cdot 87$ & 42,000 & $-37 \cdot 25$ & $88 \cdot 05$ & $473 \cdot 9$ & $-38 \cdot 35$ & $87 \cdot 84$ & $471 \cdot 1$ & $-39 \cdot 11$ & $87 \cdot 70$ & $1 \cdot 4 \%$ & 355 & $197 \cdot 6$ \\
\hline 17 & $24 \cdot 7$ & $11: 00$ & 188 & $0 \cdot 86$ & 37,000 & $-37 \cdot 88$ & $87 \cdot 05$ & $477 \cdot 2$ & -38.99 & $86 \cdot 81$ & $473 \cdot 3$ & $-39 \cdot 75$ & $86 \cdot 65$ & $-3 \cdot 2 \%$ & -839 & $184 \cdot 5$ \\
\hline 18 & $19 \cdot 7$ & $11: 10$ & 188 & $0 \cdot 87$ & 42,000 & $-37 \cdot 21$ & $88 \cdot 03$ & $474 \cdot 1$ & $-38 \cdot 31$ & $87 \cdot 82$ & $471 \cdot 3$ & $-39 \cdot 07$ & $87 \cdot 68$ & $1 \cdot 4 \%$ & 355 & $182 \cdot 6$ \\
\hline 19 & $24 \cdot 5$ & $11: 30$ & 188 & $0 \cdot 88$ & 43,000 & $-37 \cdot 44$ & $87 \cdot 92$ & $477 \cdot 5$ & $-38 \cdot 55$ & $87 \cdot 71$ & $475 \cdot 0$ & $-39 \cdot 31$ & $87 \cdot 58$ & $1 \cdot 7 \%$ & 427 & $204 \cdot 7$ \\
\hline 20 & $17 \cdot 1$ & $11: 45$ & 188 & $0 \cdot 87$ & 41,000 & $-37 \cdot 34$ & $87 \cdot 92$ & $475 \cdot 8$ & $-38 \cdot 45$ & $87 \cdot 70$ & $472 \cdot 6$ & $-39 \cdot 21$ & $87 \cdot 56$ & $0.6 \%$ & 154 & $193 \cdot 8$ \\
\hline 21 & $17 \cdot 0$ & $11: 55$ & $1 \mathrm{E} 8$ & $0 \cdot 86$ & 39,000 & $-37 \cdot 28$ & $87 \cdot 91$ & $474 \cdot 4$ & $-38 \cdot 38$ & $87 \cdot 70$ & $470 \cdot 4$ & $-39 \cdot 15$ & $87 \cdot 56$ & $-1 \cdot 0 \%$ & -254 & $18 \mathrm{E} 6$ \\
\hline 22 & $17 \cdot 0$ & $12 \cdot 05$ & 188 & $0 \cdot 85$ & 37,000 & $-37 \cdot 27$ & $87 \cdot 91$ & $473 \cdot 2$ & $-38 \cdot 36$ & $87 \cdot 70$ & $469 \cdot 0$ & $-39 \cdot 13$ & $87 \cdot 56$ & $-2 \cdot 6 \%$ & -683 & $170 \cdot 4$ \\
\hline 23 & $16 \cdot 1$ & $12: 10$ & 188 & $0 \cdot 84$ & 35,000 & $-37 \cdot 28$ & $87 \cdot 89$ & $472 \cdot 3$ & $-38 \cdot 37$ & $87 \cdot 69$ & $467 \cdot 9$ & $-39 \cdot 13$ & $87 \cdot 55$ & $-4 \cdot 9 \%$ & -1256 & $155 \cdot 8$ \\
\hline 24 & $23 \cdot 5$ & $12: 30$ & 188 & $0 \cdot 86$ & 38,000 & $-37 \cdot 44$ & $87 \cdot 79$ & $476 \cdot 1$ & $-38 \cdot 54$ & $87 \cdot 58$ & $472 \cdot 1$ & $-39 \cdot 31$ & $87 \cdot 44$ & $-2 \cdot 1 \%$ & -533 & $189 \cdot 6$ \\
\hline 25 & $18 \cdot 0$ & $12: 40$ & 187 & $0 \cdot 87$ & 43,000 & $-36 \cdot 80$ & $88 \cdot 76$ & $473 \cdot 4$ & $-37 \cdot 90$ & $88 \cdot 58$ & $470 \cdot 5$ & $-38 \cdot 66$ & $88 \cdot 46$ & $2 \cdot 0 \%$ & 517 & $184 \cdot 7$ \\
\hline 26 & $23 \cdot 6$ & $12: 40$ & 188 & $0 \cdot 85$ & 36,000 & $-37 \cdot 44$ & $87 \cdot 78$ & $475 \cdot 1$ & $-38 \cdot 54$ & $87 \cdot 58$ & $471 \cdot 0$ & $-39 \cdot 30$ & $87 \cdot 43$ & $-4 \cdot 0 \%$ & -1034 & $173 \cdot 8$ \\
\hline 27 & $24 \cdot 2$ & $12: 45$ & 187 & $0 \cdot 86$ & 41,000 & $-36 \cdot 73$ & $88 \cdot 76$ & $471 \cdot 6$ & $-37 \cdot 82$ & $88 \cdot 58$ & $468 \cdot 4$ & $-38 \cdot 59$ & $88 \cdot 46$ & $1 \cdot 0 \%$ & 268 & 1810 \\
\hline 28 & 171 & $13 \cdot 15$ & 187 & $0 \cdot 87$ & 42,000 & -36.93 & $88 \cdot 65$ & 4748 & -3803 & $88 \cdot 47$ & 4720 & -3880 & $88 \cdot 35$ & $1 \cdot 4 \%$ & 358 & $194 \cdot 7$ \\
\hline 29 & $17 \cdot 8$ & $13: 25$ & 187 & $0 \cdot 86$ & 40,000 & $-36 \cdot 86$ & $88 \cdot 65$ & $473 \cdot 2$ & $-37 \cdot 96$ & $88 \cdot 47$ & $469 \cdot 9$ & $-38 \cdot 73$ & $88 \cdot 34$ & $0 \cdot 1 \%$ & 34 & $185 \cdot 4$ \\
\hline 30 & $21 \cdot 5$ & $13: 35$ & 187 & $0 \cdot 85$ & 38,000 & $-36 \cdot 83$ & $88 \cdot 64$ & $471 \cdot 8$ & $-37 \cdot 92$ & $88 \cdot 46$ & $467 \cdot 9$ & $-38 \cdot 69$ & $88 \cdot 33$ & $-1 \cdot 5 \%$ & -386 & $174 \cdot 3$ \\
\hline 31 & $21 \cdot 6$ & $13: 40$ & 187 & $0 \cdot 84$ & 36,000 & $-36 \cdot 84$ & 88.64 & $470 \cdot 6$ & $-37 \cdot 93$ & $88 \cdot 46$ & $465 \cdot 8$ & $-38 \cdot 69$ & $88 \cdot 33$ & $-3 \cdot 4 \%$ & -869 & $158 \cdot 3$ \\
\hline 32 & $22 \cdot 0$ & $13: 50$ & 187 & $0 \cdot 83$ & 34,000 & $-36 \cdot 87$ & $88 \cdot 63$ & $469 \cdot 7$ & $-37 \cdot 96$ & $88 \cdot 45$ & $464 \cdot 0$ & $-38 \cdot 72$ & $88 \cdot 32$ & $-5 \cdot 9 \%$ & -1514 & $144 \cdot 8$ \\
\hline 33 & $23 \cdot 9$ & $14: 00$ & 187 & $0 \cdot 86$ & 39,000 & $-37 \cdot 01$ & $88 \cdot 54$ & $474 \cdot 9$ & $-38 \cdot 12$ & $88 \cdot 36$ & $471 \cdot 5$ & $-38 \cdot 88$ & $88 \cdot 23$ & $-10 \%$ & -254 & $192 \cdot 4$ \\
\hline 34 & $20 \cdot 7$ & $14: 45$ & 186 & $0 \cdot 87$ & 43,000 & $-36 \cdot 51$ & $89 \cdot 37$ & $474 \cdot 6$ & $-37 \cdot 61$ & $89 \cdot 22$ & $471 \cdot 3$ & $-38 \cdot 37$ & $89 \cdot 12$ & $2 \cdot 0 \%$ & 520 & $196 \cdot 5$ \\
\hline 35 & $19 \cdot 4$ & $14: 55$ & 186 & $0 \cdot 86$ & 41,000 & $-36 \cdot 44$ & $89 \cdot 37$ & $472 \cdot 5$ & $-37 \cdot 53$ & $89 \cdot 22$ & $469 \cdot 1$ & $-38 \cdot 30$ & $89 \cdot 11$ & $1 \cdot 0 \%$ & 268 & $185 \cdot 5$ \\
\hline 36 & $24 \cdot 6$ & $15: 05$ & 186 & $0 \cdot 86$ & 39,000 & -3638 & $29 \cdot 37$ & $470 \cdot 5$ & $-37 \cdot 48$ & $89 \cdot 21$ & $467 \cdot 1$ & $-38 \cdot 24$ & $89 \cdot 10$ & $-0 \cdot 5 \%$ & -116 & $177 \cdot 7$ \\
\hline 37 & $23 \cdot 6$ & $15: 45$ & 185 & $0 \cdot 86$ & 43,000 & $-35 \cdot 87$ & $90 \cdot 18$ & $471 \cdot 1$ & $-36 \cdot 97$ & $90 \cdot 05$ & $466 \cdot 7$ & $-37 \cdot 73$ & $89 \cdot 97$ & $2 \cdot 3 \%$ & 604 & $185 \cdot 9$ \\
\hline 38 & $22 \cdot 5$ & $16: 20$ & 185 & $0 \cdot 86$ & 42,000 & $-36 \cdot 01$ & $90 \cdot 09$ & $472 \cdot 1$ & $-37 \cdot 11$ & $89 \cdot 96$ & $467 \cdot 9$ & $-37 \cdot 88$ & $89 \cdot 88$ & $1 \cdot 8 \%$ & 461 & $186 \cdot 8$ \\
\hline
\end{tabular}


Table 8. Flight level distribution of the consistent MH370 trajectory solutions.

\begin{tabular}{|c|c|c|c|c|c|c|c|c|c|c|c|c|c|c|c|c|c|c|c|c|}
\hline $\begin{array}{l}F L \\
\text { Number of solution } \varepsilon<25 \mathrm{~km} \\
\text { Average } \varepsilon\end{array}$ & & $\begin{array}{c}340 \\
3 \\
19 \cdot 41\end{array}$ & & $\begin{array}{c}350 \\
2 \\
16 \cdot 22\end{array}$ & & $\begin{array}{c}360 \\
4 \\
20 \cdot 87\end{array}$ & & $\begin{array}{c}370 \\
3 \\
19 \cdot 86\end{array}$ & & $\begin{array}{c}380 \\
4 \\
21 \cdot 54\end{array}$ & & $\begin{array}{c}390 \\
4 \\
21 \cdot 32\end{array}$ & & $\begin{array}{c}400 \\
3 \\
18 \cdot 73\end{array}$ & & $\begin{array}{c}410 \\
4 \\
20 \cdot 53\end{array}$ & & $\begin{array}{c}420 \\
6 \\
21 \cdot 57\end{array}$ & & $\begin{array}{c}430 \\
5 \\
21 \cdot 65\end{array}$ \\
\hline$\varepsilon$ & $\begin{array}{r}3 \\
15 \\
32\end{array}$ & $\begin{array}{r}22 \\
13 \cdot 92 \\
22 \cdot 01\end{array}$ & $\begin{array}{r}8 \\
23\end{array}$ & $\begin{array}{l}16 \cdot 36 \\
16 \cdot 08\end{array}$ & $\begin{array}{r}2 \\
14 \\
26 \\
31\end{array}$ & $\begin{array}{l}23 \cdot 31 \\
14 \cdot 93 \\
23 \cdot 64 \\
21 \cdot 61\end{array}$ & $\begin{array}{r}7 \\
17 \\
22\end{array}$ & $\begin{array}{l}17 \cdot 94 \\
24 \cdot 66 \\
16 \cdot 98\end{array}$ & $\begin{array}{r}1 \\
13 \\
24 \\
30\end{array}$ & $\begin{array}{l}24 \cdot 93 \\
16 \cdot 24 \\
23 \cdot 45 \\
21 \cdot 54\end{array}$ & $\begin{array}{r}6 \\
21 \\
33 \\
36\end{array}$ & $\begin{array}{l}19 \cdot 83 \\
16 \cdot 99 \\
23 \cdot 88 \\
24 \cdot 58\end{array}$ & $\begin{array}{r}5 \\
12 \\
29\end{array}$ & $\begin{array}{l}20 \cdot 79 \\
17 \cdot 64 \\
17 \cdot 75\end{array}$ & $\begin{array}{l}10 \\
20 \\
27 \\
35\end{array}$ & $\begin{array}{l}21 \cdot 49 \\
17 \cdot 05 \\
24 \cdot 18 \\
19 \cdot 41\end{array}$ & $\begin{array}{r}4 \\
11 \\
16 \\
18 \\
28 \\
38\end{array}$ & $\begin{array}{l}24 \cdot 33 \\
23 \cdot 88 \\
22 \cdot 03 \\
19 \cdot 65 \\
17 \cdot 08 \\
22 \cdot 47\end{array}$ & $\begin{array}{r}9 \\
19 \\
25 \\
34 \\
37\end{array}$ & $\begin{array}{l}21 \cdot 46 \\
24 \cdot 49 \\
18 \cdot 01 \\
20 \cdot 67 \\
23 \cdot 63\end{array}$ \\
\hline
\end{tabular}




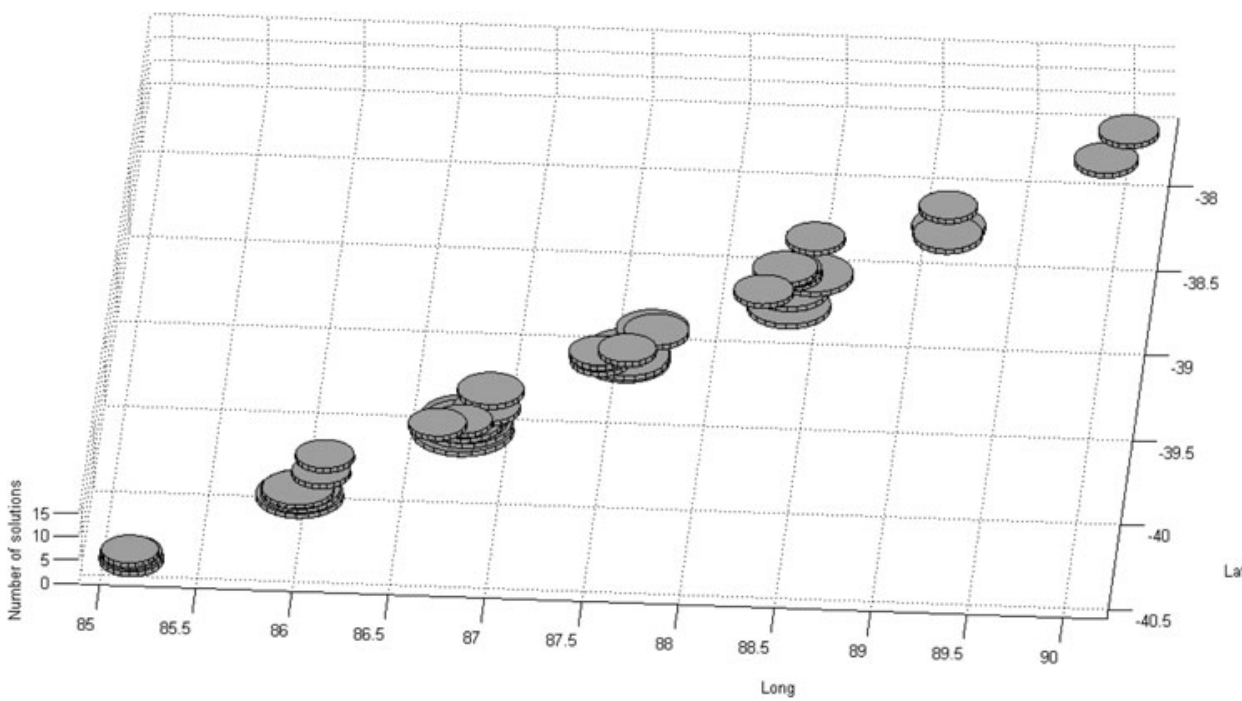

Figure 4. Position of the end of flight $(E)$ for each of the 38 consistent solutions.

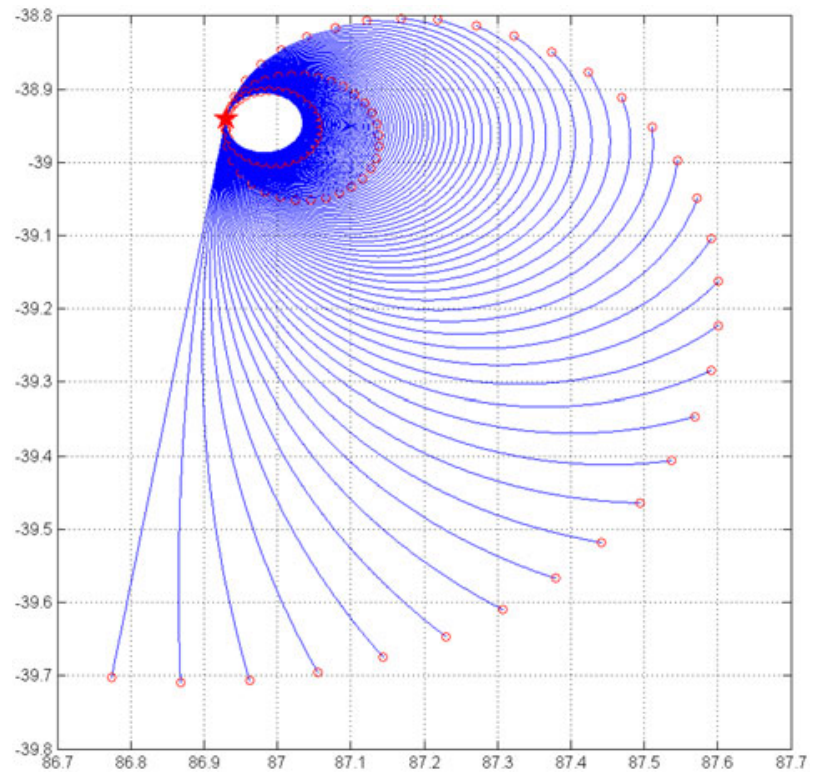

Figure 5. The locus of the end of flight positions $\left(E^{*}\right)$ for solution 11 considering a constant angular velocity turn during glide descent; the circles represent the possible points of impact for each respective angular velocity. 


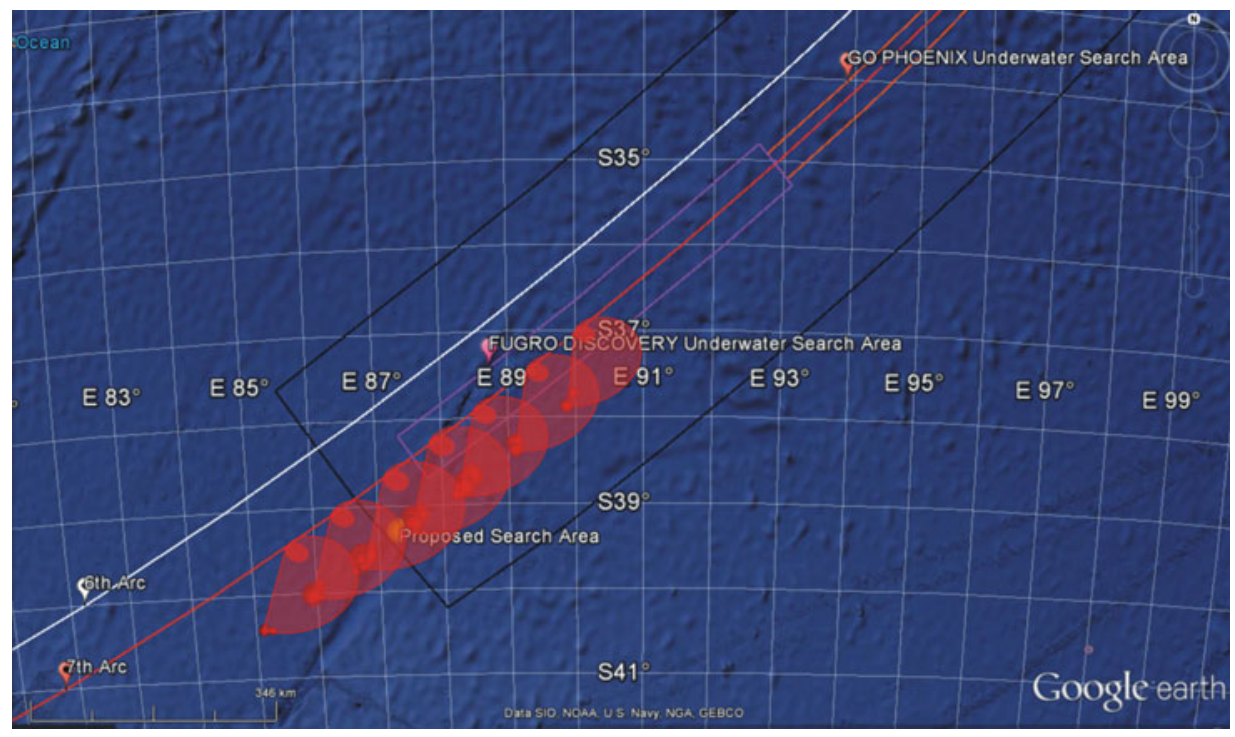

Figure 6. The end of flight point $(E)$ for each of the 38 consistent solutions (discs); the weighted average of these points is represented by a light colour disc; the transparent areas resulting from the turning glide descent model (Figure 5) were positioned on the calculated end of flight points to give a probable area of impact; the ellipses on the $7^{\text {th }}$ arc represent the most probable areas of impact.

the top of descent $\left(t_{\mathrm{G}^{*}}\right)$ calculated with the integration of the fuel flow until the moment of fuel exhaust. The relative error ranges between $-7 \cdot 2 \%$ and $+2 \cdot 3 \%$. For nine solutions (represented in yellow), the relative time error stays within $\pm 1 \%$ (254 seconds of flight in absolute value), which is remarkable, given the inherent uncertainty caused by the manoeuvres before the last turn. Moreover, these small relative errors are symmetrically distributed in the range of the consistent solutions. Such a distribution appears to validate the results of the optimisation. The relative time error filter discards the lower $F L$ solutions, such as solutions 3, 15, and 32. Also, this filter discards the lower $M$ solutions, such as $\boldsymbol{8}$ and 26 . Given the double validation, from the optimisation and the fuel burn simulation, solutions at the upper end of the $F L$ and $M$ scales stand out, e.g. solution 11.

The places where the flight might have ended in the 38 most probable scenarios are represented in Figures 4 and 5. The places seem clustered in seven isolated groups, but the gaps between these groups might be equally interesting for searching. The solutionclustering phenomenon is probably a consequence of selecting integer values for $T K$. In reality, $T K$ could have very well been a rational number, in the case of the third hypothesis of the FMS programming presented above, a "DIRECT TO" a distant point given by $L A T$ and $L O N G$. Figure 8 illustrates the whole simulated trajectory, which corresponds to one of the solutions (11). The last portion of this trajectory is made visible at a better scale in the inset.

These 38 end of flight points were calculated assuming that the glide descent was flown with a constant heading (no turn). Since the probability of a turn due to the 


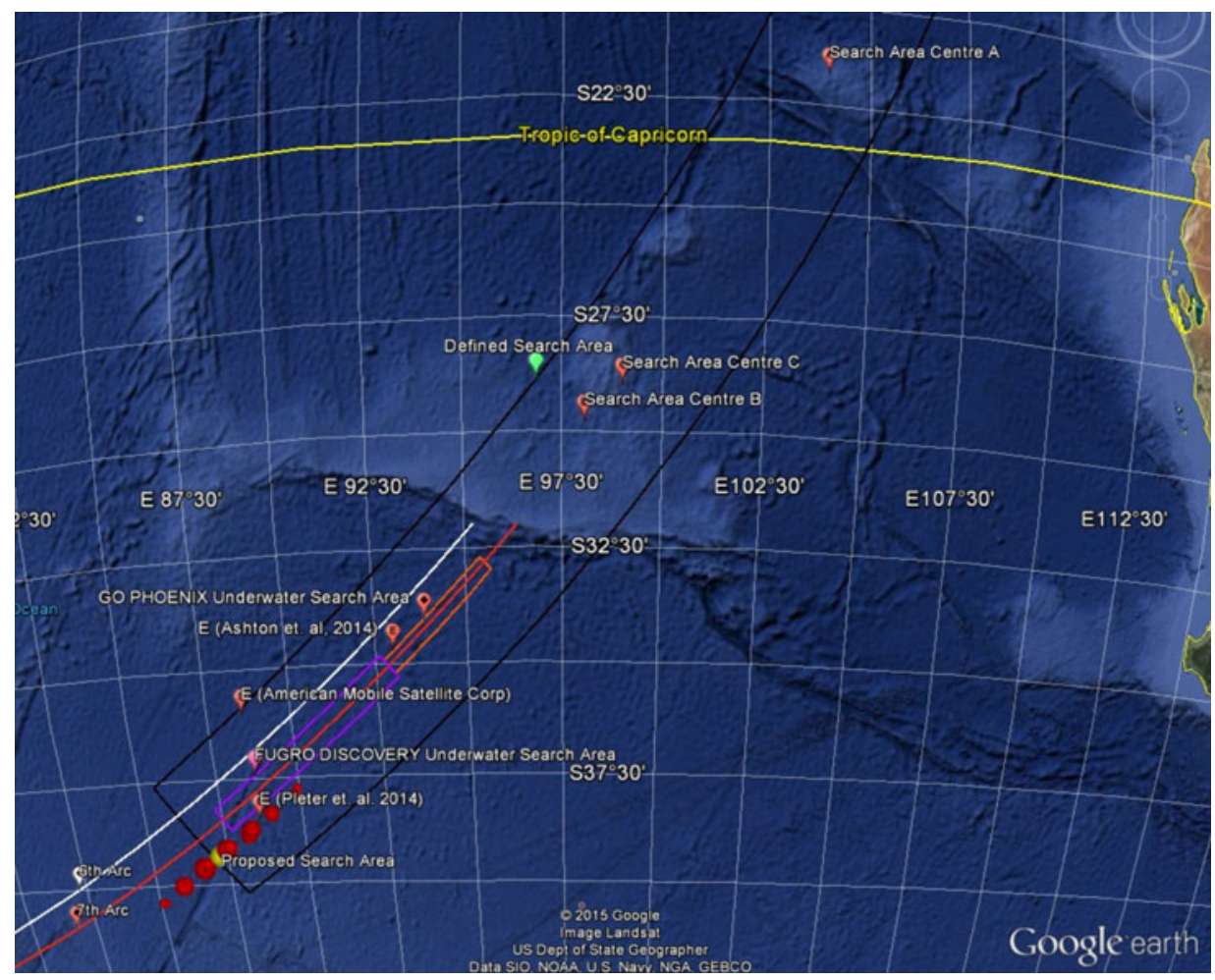

Figure 7. The end of flight point $(E)$ for each of the 38 consistent solutions, compared to the current search areas and to other results published (CNN, 2014; Australian Government, 2014; Ashton et al., 2014; Pleter and Constantinescu, 2014).

initial thrust asymmetry is high (ATSB, 2014a; 2014b - MH370 - Definition of Underwater Search Areas), and the rate of turn (the angular velocity) is not known, a locus of all potential end of flight points $\left(E^{*}\right)$ was developed and illustrated in Figure 5. All trajectories in Figure 5 correspond to the end of flight point of Solution 11, and are all turning trajectories with incremental angular velocities. The circles at the end of each same-length orthodrome trajectory represent potential points of impact with the water.

In reality, the turn could have been with variable angular velocity. The fixed angular velocity model in Figure 5 however includes in the envelope of the $E^{*}$ points all possible impact points. In Figure 6, for each cluster of $E$ solutions, the corresponding $E^{*}$ envelope was represented as a transparent area. Out of this area, the ellipses on the seventh arch illustrate the spiral dive, which could be a higher probability impact area.

In Table 8 the same 38 solutions were placed on their FLs, making it obvious that the fuel burn criterion favours the higher FLs solutions (in yellow). Flying in a denser atmosphere, although geometrically consistent with the BTOs, would have fuel starved the engines much earlier than the moment $t_{\mathrm{G}}$, which is known.

For the same solution 11, the simulated ground speed variation over the entire flight was represented in Figure 9. The ground speed is calculated as the vector addition 


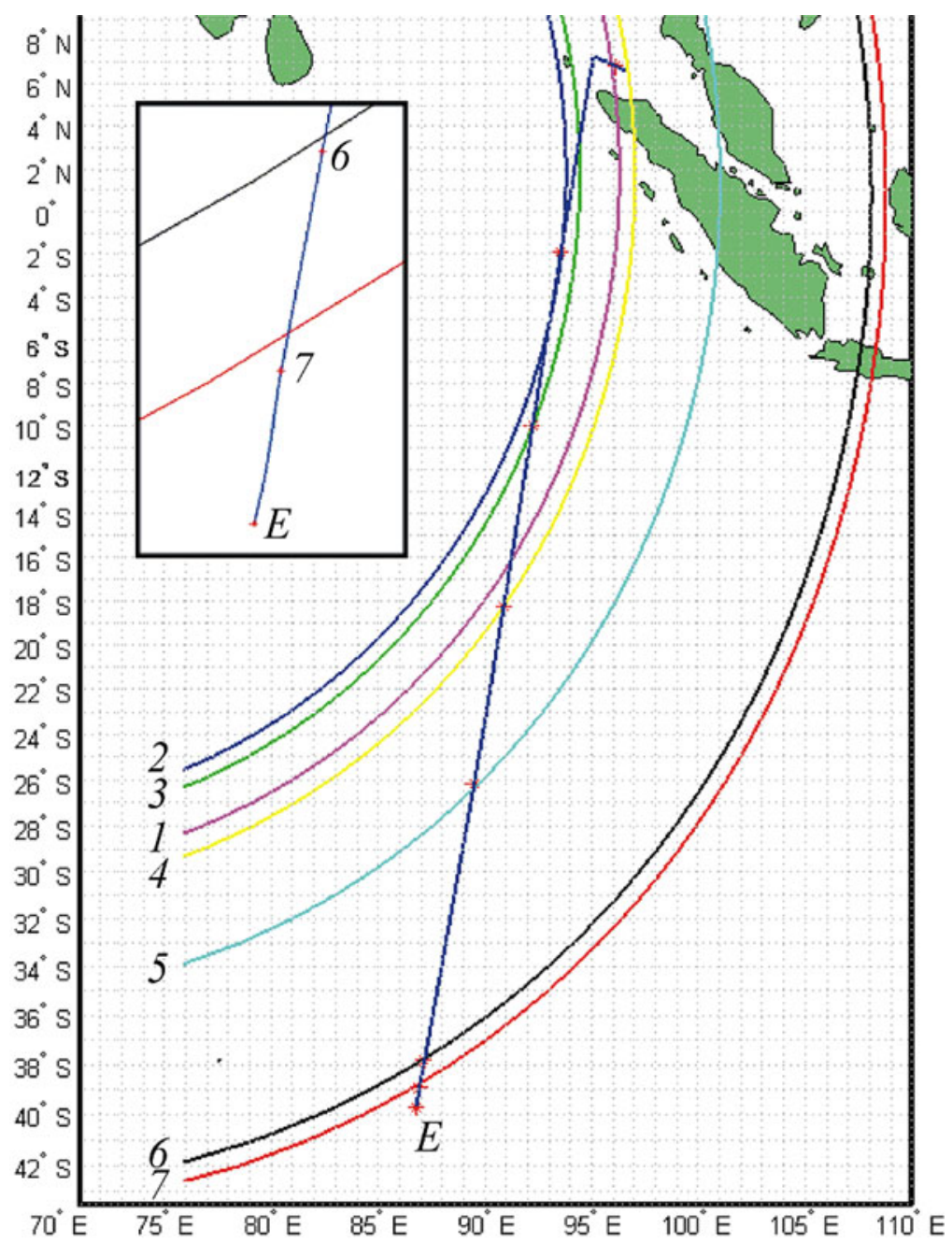

Figure 8. Quasi-circles of intersection between the satellite-centred spheres and the isobaric surface of the aircraft taken parallel to the WGS-84 rotation ellipsoid and the trajectory of MH370 as simulated for solution 11. Inset illustrates final segment with a slight drift both ways to the effect of the crosswind on the glide descent trajectory.

between the horizontal component of the true airspeed and the local wind velocity. For a possible validation of such a trajectory with a method based on $B F O$, Table 9 indicates the ground speed in the seven moments of the seven pings, decomposed in the ECEF framework.

The inclusion of the wind vector field in simulating the flight increased the relevance, as shown in Table 7. The inconsistency of the best-fit trajectories is between 6 and 15 times worse in cases where the wind vector field is not used. This validates the simulation and the use of the proper wind vector field, which is one of the few certain facts regarding this flight. 


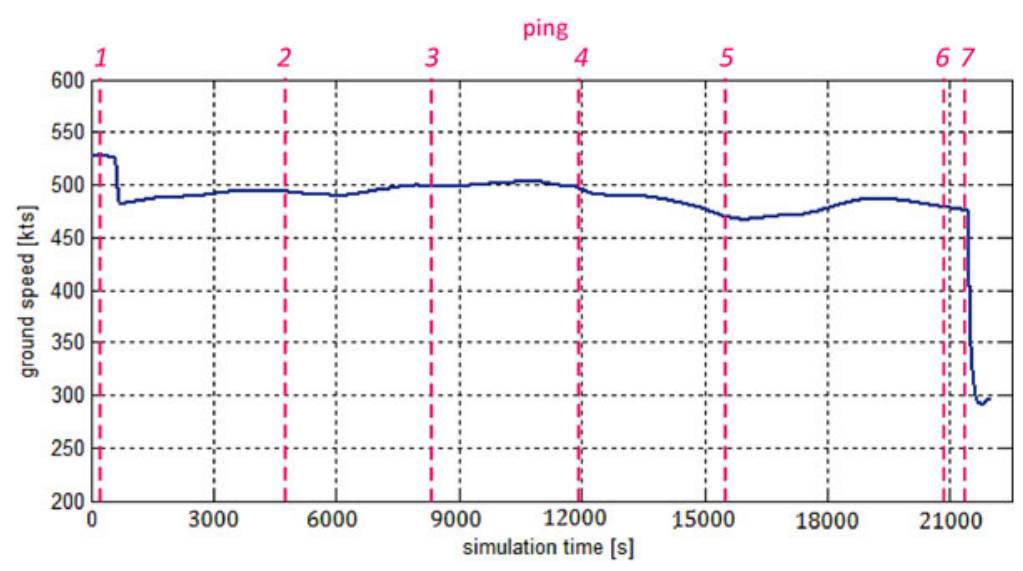

Figure 9. Simulated MH370 ground speed variation (solution 11).

Table 9. Solution 11 ground speed decomposed in ECEF reference for the seven quasi-circles.

\begin{tabular}{lrrrrrrr}
\hline ECEF & \multicolumn{1}{c}{2} & 3 & 4 & 5 & 6 & 7 \\
\hline $\mathrm{x}^{\prime}(\mathrm{m} / \mathrm{s})$ & $246 \cdot 10194$ & $41 \cdot 08357$ & $42 \cdot 09721$ & $41 \cdot 21286$ & $39 \cdot 08501$ & $33 \cdot 95766$ & $33 \cdot 19933$ \\
$\mathrm{y}^{\prime}(\mathrm{m} / \mathrm{s})$ & $12 \cdot 56416$ & $-5 \cdot 61979$ & $-42 \cdot 02263$ & $-77 \cdot 77739$ & $-104 \cdot 78226$ & $-150 \cdot 01248$ & $-152 \cdot 87285$ \\
$\mathrm{z}^{\prime}(\mathrm{m} / \mathrm{s})$ & $113 \cdot 88568$ & $-248 \cdot 75327$ & $-248 \cdot 00685$ & $-238 \cdot 06273$ & $-212 \cdot 53179$ & $-190 \cdot 78845$ & $-186 \cdot 75045$ \\
$\mathrm{t}(\mathrm{s})$ & 210 & 4743 & 8346 & 11967 & 15564 & 20940 & 21450 \\
$\mathrm{gs}(\mathrm{kts})$ & $528 \cdot 3$ & $493 \cdot 4$ & $498 \cdot 9$ & $496 \cdot 3$ & $469 \cdot 3$ & $478 \cdot 3$ & $475 \cdot 4$ \\
\hline
\end{tabular}

7. CONCLUSIONS. The method presented uses the ranges determined by the last six pings along the unknown portion of the cruise flight, avoiding calculations based on the carrier frequency drift. Thus, an issue of geometric ill conditioning of the problem is avoided (since the relative aircraft-satellite speed vector is almost perpendicular to the aircraft ground speed vector). In a multimodal optimisation loop with complete search, the flight is simulated based on a dynamic model, determining the unknowns of the flight, which best fit the known facts. Thus, the method gives simultaneously the time from the last known position until the left turn, the track, and the Mach number of the cruise. The flight level can be used as a parameter of the optimisation.

All the 38 solutions found have a flight ending point $E$ falling closely to each other, as illustrated in Figures 4, 6, and 7. The search area proposed by this paper may be approximated as a rectangle aligned with the 7 th arch, with the following corners: S39 $46^{\prime} 35^{\prime \prime}$

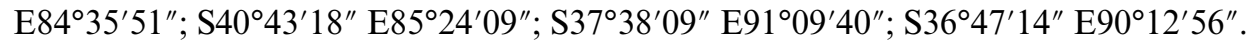

Figures 6 and 7 illustrate the most probable end of flight points calculated in this paper, in contrast to other published results (Ashton et al., 2014; Hradecky, 2014; CNN, 2014; Australian Government, 2014; Pleter and Constantinescu, 2014).

\section{ACKNOWLEDGEMENTS}

The authors wish to express their gratitude to the following contributors to their work: the reviewers of the Journal of Navigation, Capt. B787-B777 Dumitru Oprisiu, B777 Licensed Aircraft Engineer Adrian Matei, and Simon Hradecky (www.avherald.com). 


\section{REFERENCES}

Ashton, C., Schuster-Bruce, A., Colledge, G. and Dickinson, M. (2014). The Search for MH370. The Journal of Navigation, 68(1), 1-22.

ATSB. (2014a). Australian Transport Safety Bureau, MH370 - Definition of Underwater Search Areas - 26 June 2014, Accessed 6 October 2014.http://atsb.gov.au/media/5243942/ae-2014-054_mh370_-_definition_ of_underwater_search_areas_18aug2014.pdf

ATSB. (2014b). Australian Transport Safety Bureau, MH370 - Flight Path Analysis Update - 8 October 2014. http://atsb.gov.au/media/5163181/AE-2014-054_MH370\%20-flightPathAnalysisUpdate.pdf Accessed 22 November 2014

Australian Government. (2014). Department of Infrastructure and Regional Development. (2014). http:/l www.jacc.gov.au/media/maps/index.aspx Accessed 21 August 2014.

Boeing. (1992a). Boeing 777-200/-200ER Technical Characteristics. http://www.boeing.com/boeing/commercial/ 777family/pf/pf_200product.page. Accessed 1 June 2014.

Boeing. (1992b). Boeing 777 Flight Crew Training Manual. Boeing.

Bulfer, B. and Gifford, R. (1999). Big Boeing FMC User's Guide. Leading Edge Publications.

CNN. (2014). American Mobile Satellite Corp. http://edition.cnn.com/2014/06/18/world/asia/malaysiamissing-plane/index.html Accessed 10August2014.

Filippone, A. (2006). Flight Software - Sensitivity Analysis on Fuel Burn B777-300ER, The University of Manchester. http://www.flight.mace.manchester.ac.uk/aircraft-performance-software/case-studies/by-aircraft-and-route/case-study-boeing-b777.html. Accessed 5 July 2014.

Hradecky, S. (2014). Crash: Malaysia B772 over Gulf of Thailand on Mar 8th 2014, aircraft missing, data indicate flight MH-370 ended west of Australia. www.avherald.com. Accessed 13 August 2014.

INMARSAT. (2014). MH370 Data communication logs, Accessed 15 August 2014. http://www.dca.gov.my/ mainpage/MH370\%20Data \%20Communication\%20Logs.pdf

Khadilkar, H. (2011). Estimation of Aircraft Taxi-out Fuel Burn using Flight Data Recorder Archives, Masters Dissertation, Massachusetts Institute of Technology.

Malaysian Government. (2014). Office Of The Chief Inspector Of Air Accidents Ministry Of Transport Malaysia, MH 370 Preliminary Report Serial 03/2014, Accessed 11 June 2014. http://www.dca.gov.my/ MH370/Preliminary\%20Report.pdf

NOAA. (2014). NOAA National Operational Model Archive \& Distribution System. nomads.ncdc.noaa.gov/ data.php?name=access\#hires_weather_dataset. Accessed 1 June 2014.

Pereira, R. L. (2011). Validation of software for the calculation of aerodynamic coefficients, Degree Project. Linköping University.

Pleter, O. T. and Constantinescu, C. E. (2014). Possible Trajectories of Flight Malaysian 370 (plenary presentation), INCAS, International Conference of Aerospace Sciences “AEROSPATIAL 2014”. Bucharest 18-19 September 2014. 